\title{
Seismic properties of the upper mantle beneath Lanzarote (Canary Islands): Model predictions based on texture measurements by EBSD
}

\author{
Pierre Vonlanthen ${ }^{\mathrm{a}, *}$, Karsten Kunze ${ }^{\mathrm{b}}$, Luigi Burlini ${ }^{\mathrm{b}}$, Bernard Grobety ${ }^{\mathrm{a}}$ \\ a Department of Geosciences, University of Fribourg, Chemin du Musée 6, CH-1700 Fribourg, Switzerland \\ b Institute of Geology, ETH-Zentrum, Sonneggstrasse 5, CH-8092 Zürich, Switzerland
}

\begin{abstract}
We present a petrophysical analysis of upper mantle xenoliths, collected in the Quaternary alkali basalt fields (Series III and IV) from the island of Lanzarote. The samples consist of eight harzburgite and four dunite nodules, 5 to $15 \mathrm{~cm}$ in size, and exhibit a typical protogranular to porphyroclastic texture. An anomalous foliation resulting from strong recovery processes is observed in half of the specimens. The lattice preferred orientations (LPO) of olivine, orthopyroxene and clinopyroxene were measured using electron backscatter diffraction (EBSD). In most samples, olivine exhibits LPOs intermediate between the typical single crystal texture and the [100] fiber texture. Occasionally, the [010] fiber texture was also observed. Simultaneous occurrence of both types of fiber textures suggests the existence of more than one deformation regime, probably dominated by a simple shear component under low strain rate and moderate to high temperature. Orthopyroxene and clinopyroxene display a weaker but significant texture. The LPO data were used to calculate the seismic properties of the xenoliths at PT conditions obtained from geothermobarometry, and were compared to field geophysical data reported from the literature. The velocity of P-waves $(7.9 \mathrm{~km} / \mathrm{s})$ obtained for a direction corresponding to the existing seismic transect is in good agreement with the most recent geophysical interpretation. Our results are consistent with a roughly $\mathrm{W}-\mathrm{E}$ oriented fastest $\mathrm{P}$-wave propagation direction in the uppermost mantle beneath the Canary Islands, and with the lithosphere structure proposed by previous authors involving a crust-mantle boundary at around $18 \mathrm{~km}$ in depth, overlaid by intermediate material between 11 and $18 \mathrm{~km}$.
\end{abstract}

Keywords: Anomalous foliation; Lattice preferred orientation; Seismic anisotropy; Xenoliths

\section{Introduction}

Anisotropy of petrophysical properties and structure is a well established feature of the upper mantle, documented by numerous field observations (e.g. Raitt et al., 1969; Forsyth, 1975; Nataf et al., 1984; Tanimoto and Anderson, 1985; Shearer and Orcutt, 1986;

\footnotetext{
* Corresponding author.

E-mail address: pierre.vonlanthen@unifr.ch (P. Vonlanthen).
}

Montagner and Tanimoto, 1990; Silver and Chan, 1991) and laboratory experiments (e.g. Carter and Avé Lallemant, 1970; Nicolas et al., 1973; Kunze and Avé Lallemant, 1981; Chopra and Paterson, 1981; Zeuch and Green, 1984; Zhang and Karato, 1995; Tommasi et al., 1999; Zhang et al., 2000; Bystricky et al., 2000). During sea-floor spreading, plastic deformation of the lithosphere and the upper part of the asthenosphere generates a lattice preferred orientation (LPO) of upper mantle minerals. Since olivine is elastically anisotropic (Verma, 
1960; Kumazawa and Anderson, 1969) and constitutes the volumetrically dominant phase, LPO of olivine is considered the main source for seismic anisotropy in the upper mantle (Hess, 1964).

Ultramafic xenoliths represent a unique opportunity to investigate the geochemical and geophysical nature of upper mantle material. Calculations of seismic properties from xenolith LPOs help to evaluate the magnitude of seismic velocities in the upper mantle (e.g. Mainprice and Silver, 1993; Barruol and Kern, 1996; Kern et al., 1996; Ben Ismail and Mainprice, 1998; Mainprice et al., 1998; Soedjatmiko and Christensen, 2000; Saruwatari et al., 2001; Pera et al., 2003) and can be used to better constrain the interpretations inferred from field geophysical measurements. In the last few decades, the upper mantle xenoliths of Lanzarote have been investigated by numerous petrological and geochemical studies (Siena et al., 1991; Neumann et al., 1995; Thomas et al., 1999; Neumann et al., 2004). However, our knowledge on the petrophysical properties of the upper mantle beneath this island remains controversial. Using the seismic refraction method, Banda et al. (1981) calculated a very low mantle velocity of $7.4 \mathrm{~km} / \mathrm{s}$ for Pn-waves in the NNE-SSW direction. However, this interpretation was questioned recently by Dañobeitia and Canales (2000), who proposed an upper mantle velocity of 7.6$7.8 \mathrm{~km} / \mathrm{s}$ in the same direction. In this paper, we present an electron backscatter diffraction (EBSD) study carried out on 12 ultramafic xenoliths sampled on the island of Lanzarote. The objective is to measure LPOs of olivine, orthopyroxene and clinopyroxene and to infer the seismic properties of the upper mantle in depth. These results are used to better constrain the deformation regimes and the geodynamic setting of the upper mantle and are compared to the interpretations deduced from field geophysical measurements.

\section{Geological background}

The geodynamic setting of the Canary Archipelago continues to be a debated issue among earth scientists. Historically, four concepts were proposed to explain the magmatic activity of the Canary Islands: (1) the hot spot model (Morgan, 1971; Burke and Wilson, 1972; Schmincke, 1973; Vogt, 1974; Khan, 1974; Morgan, 1983), (2) the propagating fracture hypothesis, possibly related to the tectonics of the Moroccan Atlas (Dash and Bosshard, 1969; MacFarlane and Ridley, 1969; Bosshard and MacFarlane, 1970; Le Pichon and Fox, 1971; Grunau et al., 1975; Anguita and Hernán, 1975), (3) the uplift tectonic concept (Araña and Ortiz, 1986) and (4) the local extensional ridge theory (Fúster, 1975).
Among these, the hot spot model has clearly gained in popularity in the last two decades (e.g. Schmincke, 1982; Holik et al., 1991; Watts, 1994; Hoernle et al., 1995, Neumann et al., 1995; Carracedo et al., 1998; Dañobeitia and Canales, 2000; Rhodes and Davies, 2001). However, numerous inconsistencies between the evolution of the Canary Islands and the classical hot spot scheme have been reported by Hoernle and Schmincke (1993). To explain these differences, these authors suggested that the Canary Islands plume corresponds to a "blob type" (Allègre et al., 1984) hot spot, whereas others (Anguita and Hernán, 2000) proposed a unifying model partly reconciling three of the historically cited hypotheses, thus giving more weight to the regional tectonics. Whatever the scenario, it seems now widely accepted that volcanism in the Canary Islands cannot be attributed to a classical hotspot alone and is not completely independent of the regional tectonics. The question whether the importance of tectonics is major or minor has not been elucidated yet.

Lanzarote is the easternmost island of the Canary Archipelago, located about $140 \mathrm{~km}$ off the African continent in the Atlantic Ocean. Together with the island of Fuerteventura, Lanzarote represents the emergent part of the East Canary Ridge (Fig. 1), a NNE-SSW linear volcanic structure about of $400 \mathrm{~km}$ in length and $65 \mathrm{~km}$ in width (Marinoni and Pasquaré, 1994). Subaerial volcanic activity in Lanzarote dates back to the midMiocene (Abdel Monem et al., 1971; Coello et al., 1992). It can be divided into (1) a shield-building stage, mainly Miocene in age (14.5-8.7 Ma), followed by sporadic volcanic activity interrupted by long-lasting erosive periods up to the early Pliocene $(3.8 \mathrm{Ma})$, and (2) a post-shield or post-erosion stage, Plio-Quaternary in age (2.7 Ma-Recent), characterized by the formation of small NE-NNE aligned volcanoes with associated lava fields. The volcanic products of the shield-building stage are known as Series I, whereas the post-shield stage volcanics comprise the Series II, III and IV, the latter referring to the Historical volcanic products (Fúster et al., 1968). Recent eruptions on Lanzarote occurred between 1730 and 1736 and in 1824. Like the other islands of the Canaries, Lanzarote is built on a preMiocene basal complex (Fúster and Aguilar, 1965; Stillman et al., 1975; Robertson and Stillman, 1979; Robertson and Bernouilli, 1982; Le Bas et al., 1986), consisting of Cretaceous turbidites overlain by interbedded Albian-Oligocene sediments and submarine volcanics. However, the basal complex does not crop out in Lanzarote.

The crustal and upper mantle structure beneath Lanzarote was investigated by gravimetric (MacFarlane 


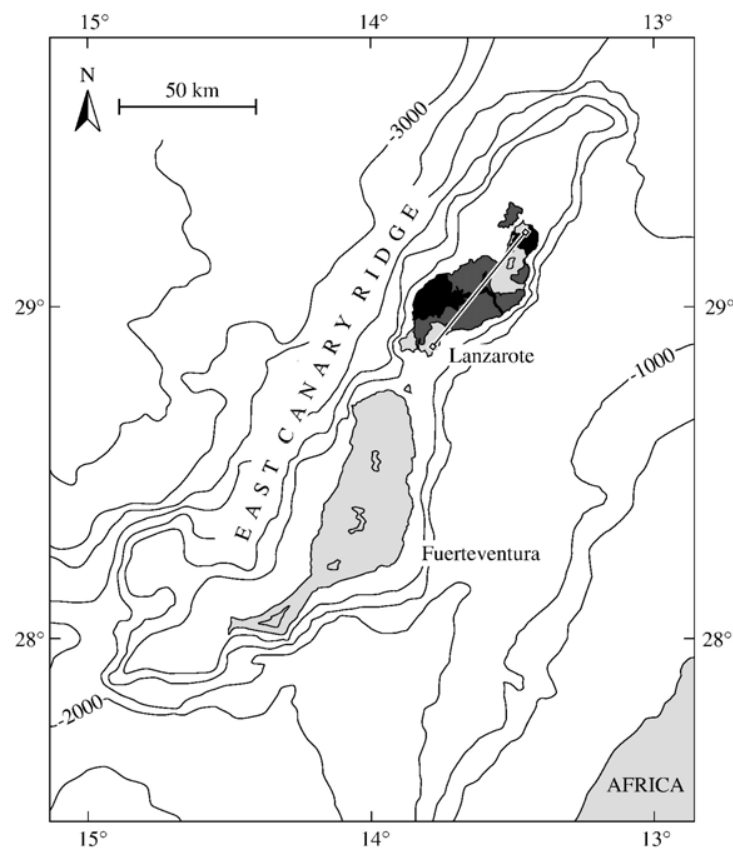

Fig. 1. Map of the East Canary Ridge with altitude contours at $500 \mathrm{~m}$ intervals. Areas above sea level are light shaded. Quaternary lava fields for Series III and IV in Lanzarote are shown in dark gray and black, respectively; the straight line represents the seismic transect of Banda et al. (1981).

and Ridley, 1969; Camacho and Vieira, 1991), seismic (Banda et al., 1981) and magnetotelluric (Ortiz et al., 1986) studies. On the basis of seismic refraction data, Banda et al. (1981) divided the crust into an upper layer, about $5 \mathrm{~km}$ in thickness, formed by pelagic and volcanoclastic sediments overlain by Tertiary and Quaternary volcanics, and a lower layer, about $6 \mathrm{~km}$ in thickness, containing the base of the ophiolitic sequence. In this interpretation, the Moho lies at a depth of $11 \mathrm{~km}$ and overlies anomalously hot upper mantle material characterized by a very low Pn-wave velocity of $7.4 \mathrm{~km} / \mathrm{s}$. However, after re-interpreting the data of Banda et al. (1981), Dañobeitia and Canales (2000) located the Moho at $18 \mathrm{~km}$, considering the material between 11 and $18 \mathrm{~km}$ as resulting from underplating. These authors hence suggested a higher Pn-wave velocity for the upper mantle $(7.6-7.8 \mathrm{~km} / \mathrm{s})$.

\section{Samples}

In this study, 12 peridotite xenoliths collected in the Quaternary lava fields (Series III and IV) of Lanzarote were examined. From these, seven samples (labeled LA) were already investigated from a geochemical point of view in a former study by Neumann et al. (1995) and were kindly put at our disposal. The other five samples (labeled PV) are part of the ETH Zurich collection.

The xenoliths of Lanzarote form rounded nodules, typically $5-15 \mathrm{~cm}$ in size, embedded in alkali basalts. Eight samples are spinel-harzburgites (PV01, PV05, PV06, PV08, LA2-4, LA6-1, LA6-35, LA8-4) and four are spinel-dunites (PV04, LA6-16, LA6-19, LA8-7) (Fig 2). According to the nomenclature of Mercier and Nicolas (1975), the fabric of the samples can be classified either as protogranular or porphyroclastic, except for sample LA8-7, which is extensively recrystallized and tends to adopt an equigranular fabric (Fig 3). A correlation exists between fabric and composition, the protogranular samples being mainly spinel-harzburgites, whereas all spinel-dunites (except PV04) are either porphyroclastic or equigranular.

The protogranular fabric (PV01, PV04, PV05, PV06, PV08, LA2-4, LA8-4) is characterized by very coarse strain-free to moderately strained olivine and orthopyroxene grains up to $15 \mathrm{~mm}$ in size. Most protogranular samples show a strong recovery texture, generally indicative of high temperature conditions typically in the order of $1200{ }^{\circ} \mathrm{C}$ (Nicolas and Poirier, 1976). If present, the subgrain boundaries are straight and widely spaced. The grain boundaries are either slightly curved, indicating migration, or straightened by grain boundary area reduction. Small rounded olivine grains showing a possible pathway of a percolating magma were also observed (Fig. 4a). Orthopyroxene often displays corroded grain shapes with embayments filled by olivine or an aggregate of secondary olivine, clinopyroxene and spinel. Clinopyroxene is generally scarce and interstitial, but may form larger subhedral grains up to $5 \mathrm{~mm}$ in size.

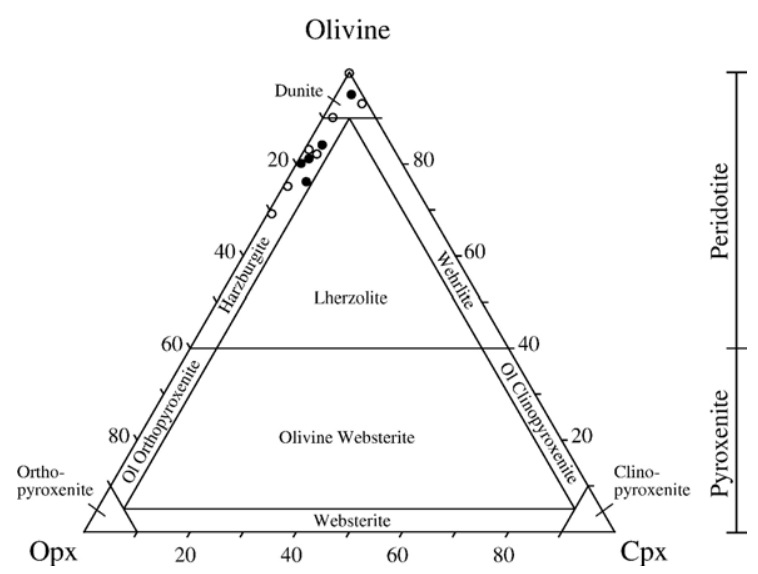

Fig. 2. Modal compositions (based on EBSD scans) for the 12 spinelperidotites from Lanzarote. The samples analyzed in the geochemical study of Neumann et al. (1995) are represented by open circles. 

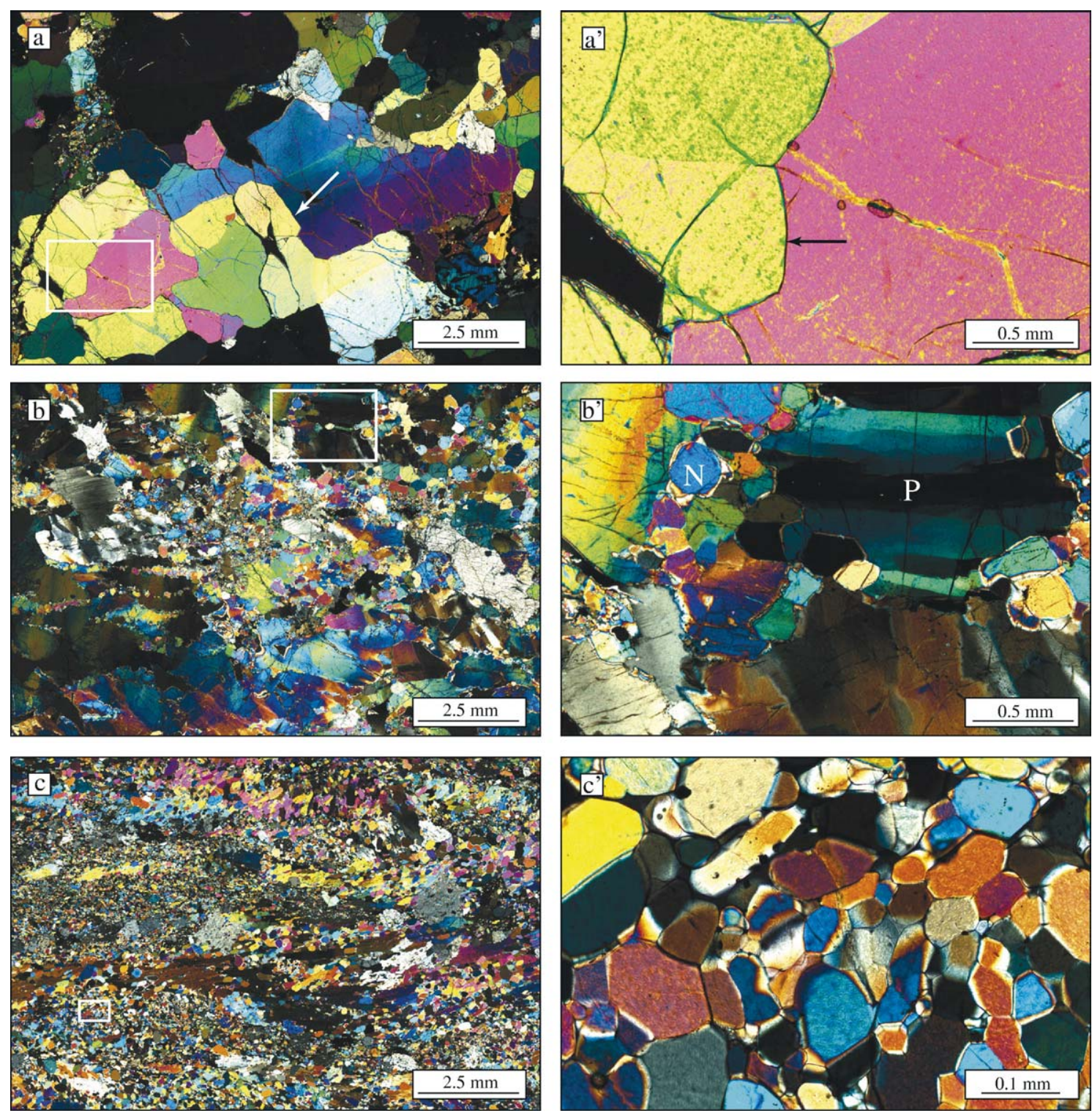

Fig. 3. Typical microstructures of Lanzarote peridotites. For each fabric type, a close-up view of the framed area in the left image is presented on the right. (a-a') Coarse-grained protogranular sample (PV06) showing clear signs of recovery: large and optically strain-free grains, widely spaced subgrain boundaries, stepwise straight grain boundaries due to area reduction (white arrow) and smoothly curved grain boundaries indicating grain boundary migration (black arrow). (b-b') Partly recrystallized porphyroclastic harzburgite (LA6-35) showing well developed and closely spaced subgrain boundaries in remnant porphyroclasts $(\mathrm{P})$. Neoblasts $(\mathrm{N})$ are optically strain-free. (c-c') Pervasively recrystallized dunite (LA8-7) equilibrated at high temperature (annealing) with a mosaic equigranular fabric. Foliation horizontal; crossed polarizers.

The porphyroclastic samples (LA6-1, LA6-16, LA6-19, LA6-35) show clear signs of plastic deformation by dislocation creep, as evidenced by undulose extinction and narrowly spaced subgrain boundaries in the coarse (up to $10 \mathrm{~mm}$ ) olivine porphyroclasts. Recrystallization into small (typically 0.1 to $1 \mathrm{~mm}$ in size) subhedral and strain-free neoblasts is strong to moderate. The porphyroclast grain boundaries are often serrated or imbricated. Little signs of recovery processes were observed in these samples. This porphyroclastic fabric is generally interpreted as the result of a deformation under moderately high temperature (typically $1000-1100{ }^{\circ} \mathrm{C}$ ), partly confirmed by the thermometric analyses of Neumann et al. (1995). In their description, the coarse, strained porphyroclasts are identified as generation I as opposed to the neoblasts of generation II. Orthopyroxene also displays large (up to $10 \mathrm{~mm}$ ) porphyroclasts of generation I, frequently with narrow exsolution lamellae of clinopyroxene and spinel. 

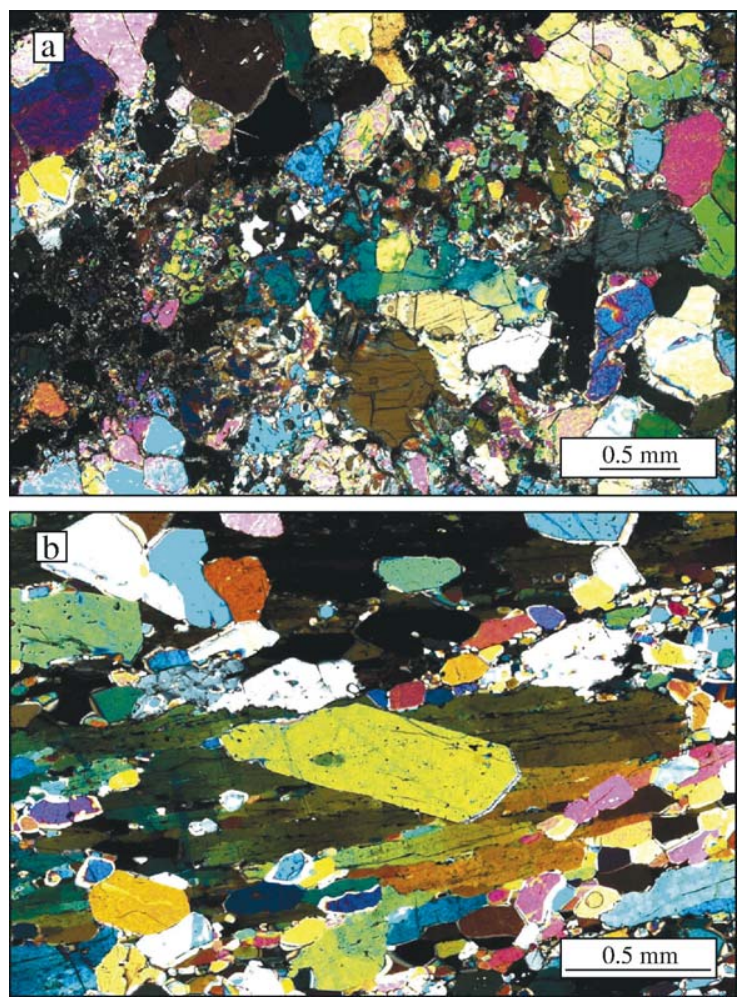

Fig. 4. (a) Recrystallization of rounded olivine grains indicating a possible pathway of percolating magma in sample PV04 (protogranular). (b) Subautomorphic olivine grain truncating a former porphyroclast in sample LA8-7 (equigranular). Crossed polarizers.

Rare kink bands are observed in orthopyroxene of sample LA6-35. Partial or complete recrystallization of orthopyroxene in aggregates of minute olivine, orthopyroxene, clinopyroxene and spinel is commonly observed. In most samples, clinopyroxene occurs either as neoblasts, usually smaller than $0.1 \mathrm{~mm}$, or as exsolution lamellae in orthopyroxene.

At increasing strain, the porphyroclastic fabric evolves towards a dynamically recrystallized and equigranular microstructure (LA8-7). The neoblasts form a groundmass of equi-dimensional, optically strain-free olivine grains, occasionally embedding relicts of earlier porphyroclasts. Recrystallization by subgrain rotation is predominant, as evidenced by bands or patchy areas containing newly formed neoblasts with similar crystallographic orientations. However, tabular shaped "subautomorphic" olivine (Boullier and Nicolas, 1975; Mercier, 1979) truncating the residual porphyroclasts (Fig. 4b) clearly indicates a later growth from recrystallized nuclei.

In both protogranular and porphyroclastic fabrics, the shape preferred orientation of the large olivine grains marks a weak foliation, which is barely visible in hand specimen, but obvious in thin section and EBSD maps. Most protogranular samples, however, show an anomalous grain shape foliation relative to olivine LPO, which is oriented normal to the olivine [100] pole maximum. This feature, already mentioned by Coisy (1977) in peridotites from the French Massif Central, is discussed in detail in Section 6.2.

Geothermometry (Neumann et al., 1995) performed on the porphyroclast and neoblast assemblages revealed an extremely wide spectrum of equilibration temperatures, ranging from 750 to $1290{ }^{\circ} \mathrm{C}$. Geobarometric analyses based on microthermometric measurements on the densest $\mathrm{CO}_{2}$-fluid inclusions indicated a pressure of 0.6-0.8 GPa (20-26 km depth) for the xenoliths, suggesting a very high geothermal gradient beneath Lanzarote, with a temperature of about $1100^{\circ} \mathrm{C}$ at $26 \mathrm{~km}$ depth (Neumann et al., 1995). Trace elements and isotope analysis of ultramafic xenoliths revealed that the upper mantle beneath the Canary Islands became strongly depleted during the opening of the Atlantic Ocean, after about 25-30\% partial melting. Metasomatic processes related to the intrusion of carbonate-rich melts, attributed to Cenozoic intraplate volcanism, were also put forward by Neumann et al. (2004).

\section{Methodology}

\subsection{LPO measurement and representation}

The lattice preferred orientations (LPOs) of olivine, orthopyroxene and clinopyroxene were measured by electron backscatter diffraction (EBSD). The EBSD technique (e.g. Venables and Harland, 1973; Adams et al., 1993; Prior et al., 1999) is based on automatic analysis of Kikuchi-type diffraction patterns generated by backscattered electrons. For each point of analysis, the crystallographic orientation, commonly expressed by Euler angles $\left(\varphi_{1}, \Phi, \varphi_{2}\right.$; Bunge, 1982), is determined after indexing of the corresponding diffraction pattern. All EBSD data were collected at the University of Fribourg using a Philips FEI XL30 SFEG Sirion ${ }^{\circledR}$ scanning electron microscope (SEM). The best results were obtained with an acceleration voltage of 20 or $25 \mathrm{kV}$ for a probe current of $20 \mathrm{nA}$. Recording and processing of the EBSD patterns were performed with the EDAX (TSL) OIM $3.5^{\circledR}$ software package.

EBSD measurements were carried out on massive sample blocks, approximately $4 \times 2 \times 1 \mathrm{~cm}$ in size. Because Lanzarote xenoliths are often brittle and prone to break up when manipulated, each block was impregnated with epoxy glue before surface polishing. 
Table 1

Characteristics from EBSD scans for the 12 Lanzarote xenoliths

\begin{tabular}{|c|c|c|c|c|c|c|c|c|c|c|}
\hline \multirow[t]{2}{*}{ Sample } & \multirow[t]{2}{*}{ Rock type } & \multirow[t]{2}{*}{ Fabric } & \multirow[t]{2}{*}{ Measurements } & \multirow{2}{*}{$\begin{array}{l}\text { Measurements } \\
\text { with } \mathrm{CI}>0.2\end{array}$} & \multirow{2}{*}{$\begin{array}{l}\text { Average } \\
\text { CI }\end{array}$} & \multirow{2}{*}{$\begin{array}{l}\text { Grain } \\
\text { total }\end{array}$} & \multirow{2}{*}{$\begin{array}{l}\text { Area } \\
{\left[\mathrm{cm}^{2}\right]}\end{array}$} & \multicolumn{3}{|c|}{ Phase [vol.\%] } \\
\hline & & & & & & & & $\mathrm{Ol}$ & Opx & $\mathrm{Cpx}$ \\
\hline PV01 & Harzburgite & Protogranular & 25696 & $12245(48 \%)$ & 0.23 & 335 & 2.54 & 76 & 20 & 4 \\
\hline PV04 & Dunite & Protogranular & 27336 & $19590(72 \%)$ & 0.34 & 350 & 2.70 & 95 & 2 & 3 \\
\hline PV05 & Harzburgite & Protogranular & 56776 & $41737(74 \%)$ & 0.36 & 450 & 5.62 & 84 & 13 & 3 \\
\hline PV06 & Harzburgite & Protogranular & 58256 & $38975(67 \%)$ & 0.33 & 397 & 5.76 & 81 & 17 & 2 \\
\hline PV08 & Harzburgite & Protogranular & 55266 & $41691(75 \%)$ & 0.37 & 396 & 5.48 & 80 & 19 & 1 \\
\hline LA2-4 & Harzburgite & Protogranular & 62586 & $43020(69 \%)$ & 0.33 & 638 & 6.21 & 69 & 30 & 1 \\
\hline LA6-1 & Harzburgite & Porphyroclastic & 50406 & $34147(68 \%)$ & 0.34 & 2964 & 5.00 & 83 & 16 & 1 \\
\hline LA6-16 & Dunite & Porphyroclastic & 30261 & $19384(64 \%)$ & 0.31 & 358 & 2.99 & 93 & 1 & 6 \\
\hline LA6-19 & Dunite & Porphyroclastic & 57316 & $43759(76 \%)$ & 0.40 & 1160 & 5.68 & 100 & 0 & 0 \\
\hline LA6-35 & Harzburgite & Porphyroclastic & 41396 & $29856(72 \%)$ & 0.36 & 3000 & 4.09 & 75 & 24 & 1 \\
\hline LA8-4 & Harzburgite & Protogranular & 53856 & $35881(67 \%)$ & 0.32 & 715 & 5.33 & 82 & 15 & 3 \\
\hline LA8-7 & Dunite & Equigranular & 48546 & $35099(72 \%)$ & 0.37 & 4932 & 4.18 & 90 & 8 & 2 \\
\hline
\end{tabular}

Only grains with a minimum of 2-3 (equigranular) respectively 7-10 (protogranular) successful measurements were retained for the grain count statistics, in order to avoid artificial overestimations of the number of grains.

Usual grinding and polishing with diamond paste was followed by lapping for $10 \mathrm{~h}$ using a colloidal silica suspension (grain size $25 \mathrm{~nm}$ ). To avoid specimen charging, the sample surface was coated with a $2 \mathrm{~nm}$ carbon layer and connected with silver paint to the sample holder.

For statistical reasons, LPO analysis of a polycrystalline sample requires that the orientation of a sufficient number of grains is measured. According to Ben Ismail and Mainprice (1998), at least 100 to 150 grains should be analyzed in order to obtain a representative LPO of a rock. Due to the coarse grain size distribution of most Lanzarote xenoliths, data were collected on grids with $100 \mu \mathrm{m}$ steps using a computer-controlled SEM stage. This allowed the measurement and mapping of several hundreds of grains per sample on areas ranging from $14.5 \times 17.5 \mathrm{~mm}^{2}$ for the smallest specimen and up to $17.0 \times 36.5 \mathrm{~mm}^{2}$ for the largest. For each point of analysis, a Confidence Index (CI) expresses the reliability of indexing. CI values are always comprised between 0 and 1 and experience has shown that a pattern with a CI $>0.2$ is almost certainly indexed correctly. In our samples, the average Confidence Index (CI) was between 0.31 (LA6-16) and 0.40 (LA6-19) except for sample PV01 (0.23). The points of the scans with a $\mathrm{CI}<0.2$ were not considered for further texture analysis. The consistently high CI values of our EBSD data make indexing errors due to pseudo-symmetry of olivine very unlikely. Wrong indexing is generally accompanied by a very low $\mathrm{CI}$, due to the fact that more than one solution with similar likelihood is proposed during the indexing procedure. As a consequence, the quality of EBSD maps would markedly deteriorate, since large grains will typically contain speckled points indexed by any of the pseudo-symmetric orientations. Such features are never observed in this study. The scanning parameters, average CI values and modal composition for the 12 Lanzarote xenoliths are presented in Table 1.

In order to obtain data compatible with the format of most of the already published EBSD analyses on upper mantle material (e.g. Mainprice and Silver, 1993; Ben Ismaïl and Mainprice, 1998; Mainprice et al., 2000; Vauchez and Garrido, 2001; Pera et al., 2003), the Unicef Careware software package (Mainprice, 1999) was chosen to generate orientation distribution functions (ODF) and to calculate seismic properties. The ODF $f(g)$, defined by Bunge (1982) as the volume fraction of orientations in the interval between $g$ and $g+\mathrm{d} g$ in a space containing all possible orientations, is given by:

$\Delta V / V=\int f(g) \mathrm{d} g$

$\mathrm{d} g=\frac{1}{8 \pi^{2}} \sin \Phi d \varphi_{1} \mathrm{~d} \Phi d \varphi_{2}$

where $\Delta V / V$ is the volume fraction of crystals with orientation $g, f(g)$ is the texture function and $\mathrm{d} g$ is the volume of the region of integration in orientation space. Spherical harmonics truncated at an expansion degree of $L_{\max }=22$ with a default Gaussian half-width of $8.5^{\circ}$ were used.

The strength of the texture was expressed by the texture index $J$ calculated as the mean square value of the ODF (Bunge, 1982):

$J=\int f(g)^{2} \mathrm{~d} g$ 
Table 2

Density and elastic constants of olivine, orthopyroxene and clinopyroxene (a) for room conditions and (b) derived for upper mantle $P / T$ conditions of $0.7 \mathrm{GPa}$ and $1000^{\circ} \mathrm{C}$

\begin{tabular}{|c|c|c|c|c|c|c|c|c|c|c|c|c|c|c|c|c|c|c|}
\hline \multirow{2}{*}{$\frac{\text { (a) }}{C_{\mathrm{ij}}\left(P_{0}, T_{0}\right)}$} & \multicolumn{6}{|c|}{ Olivine $\left(\rho_{0}=3.355\left[\mathrm{~g} / \mathrm{cm}^{3}\right]\right)$} & \multicolumn{6}{|c|}{ Orthopyroxene $\left(\rho_{0}=3.370\left[\mathrm{~g} / \mathrm{cm}^{3}\right]\right)$} & \multicolumn{6}{|c|}{ Clinopyroxene $\left(\rho_{0}=3.327\left[\mathrm{~g} / \mathrm{cm}^{3}\right]\right)$} \\
\hline & 320.5 & 68.1 & 71.6 & 0.0 & 0.0 & 0.0 & 236.9 & 79.9 & 63.2 & 0.0 & 0.0 & 0.0 & 237.8 & 83.5 & 80.0 & 0.0 & 9.0 & 0.0 \\
\hline & 68.1 & 196.5 & 76.8 & 0.0 & 0.0 & 0.0 & 79.9 & 180.5 & 56.8 & 0.0 & 0.0 & 0 . & 83.5 & 183.6 & 59.9 & 0.0 & 9.5 & 0.0 \\
\hline & 71.6 & 76.8 & 233.5 & 0.0 & 0.0 & 0.0 & 63.2 & 56.8 & 230.4 & 0.0 & 0.0 & 0.0 & 80.0 & 59.9 & 229.5 & 0.0 & 48.1 & 0.0 \\
\hline & 0.0 & 0.0 & 0.0 & 64.0 & 0.0 & 0.0 & 0.0 & 0.0 & 0.0 & 84.3 & 0.0 & 0.0 & 0.0 & 0.0 & 0.0 & 76.5 & 0.0 & 8.4 \\
\hline & 0.0 & 0.0 & 0.0 & 0.0 & 77.0 & 0.0 & 0.0 & 0.0 & 0.0 & 0.0 & 79.4 & 0.0 & 9.0 & 9.5 & 48.1 & 0.0 & 73.0 & 0.0 \\
\hline & 0.0 & 0.0 & 0.0 & 0.0 & 0.0 & 78.7 & 0.0 & 0.0 & 0.0 & 0.0 & 0.0 & 80.1 & 0.0 & 0.0 & 0.0 & 8.4 & 0.0 & 81.6 \\
\hline
\end{tabular}

\begin{tabular}{|c|c|c|c|c|c|c|c|c|c|c|c|c|c|c|c|c|c|c|}
\hline \multirow{2}{*}{$\frac{(\mathrm{b})}{C_{\mathrm{ij}}(P, T)}$} & \multicolumn{6}{|c|}{ Olivine $\left(\rho(P, T)=3.248\left[\mathrm{~g} / \mathrm{cm}^{3}\right]\right)$} & \multicolumn{6}{|c|}{ Orthopyroxene $\left(\rho(P, T)=3.276\left[\mathrm{~g} / \mathrm{cm}^{3}\right]\right)$} & \multicolumn{6}{|c|}{ Clinopyroxene $\left(\rho(P, T)=3.214\left[\mathrm{~g} / \mathrm{cm}^{3}\right]\right)$} \\
\hline & 289.6 & 60.2 & 64.9 & 0.0 & 0.0 & 0.0 & 209.8 & 63.6 & 36.8 & 0.0 & 0.0 & 0.0 & 207.0 & 67.0 & 52.2 & 0.0 & 8.3 & 0.0 \\
\hline & 60.2 & 173.4 & 73.0 & 0.0 & 0.0 & 0.0 & 63.6 & 154.7 & 51.4 & 0.0 & 0.0 & 0.0 & 67.0 & 156.9 & 52.3 & 0.0 & 8.4 & 0.0 \\
\hline & 64.9 & 73.0 & 209.2 & 0.0 & 0.0 & 0.0 & 36.8 & 51.4 & 187.8 & 0.0 & 0.0 & 0.0 & 52.2 & 52.3 & 182.5 & 0.0 & 47.6 & 0.0 \\
\hline & 0.0 & 0.0 & 0.0 & 51.7 & 0.0 & 0.0 & 0.0 & 0.0 & 0.0 & 72.4 & 0.0 & 0.0 & 0.0 & 0.0 & 0.0 & 65.5 & 0.0 & 9.1 \\
\hline & 0.0 & 0.0 & 0.0 & 0.0 & 63.9 & 0.0 & 0.0 & 0.0 & 0.0 & 0.0 & 66.5 & 0.0 & 8.3 & 8.4 & 47.6 & 0.0 & 60.5 & 0.0 \\
\hline & 0.0 & 0.0 & 0.0 & 0.0 & 0.0 & 64.0 & 0.0 & 0.0 & 0.0 & 0.0 & 0.0 & 67.9 & 0.0 & 0.0 & 0.0 & 9.1 & 0.0 & 69.1 \\
\hline
\end{tabular}

Density and elastic constant variations as a function of pressure and temperature were calculated using the equations (1) and (2), respectively.

(1) $\rho(P, T)=\rho_{0}\left\{\left[1+\left(K^{\prime} / K\right)\left(P-P_{0}\right)\right]^{1 / K^{\prime}}\left[1-\alpha_{\mathrm{av}}\left(T-T_{0}\right)\right]\right\}$.

(2) $C_{\mathrm{ij}}(P, T)=C_{\mathrm{ij}}\left(P_{0}, T_{0}\right)+\left(\mathrm{d} C_{\mathrm{ij}} / \mathrm{d} P\right)\left(P-P_{0}\right)+1 / 2\left(\mathrm{~d}^{2} C_{\mathrm{ij}} / \mathrm{d} P^{2}\right)\left(P-P_{0}\right)^{2}+\left(\mathrm{d} C_{\mathrm{ij}} / \mathrm{d} T\right)\left(T-T_{0}\right)$.

with:

$\rho(P, T)=$ density derived for $P / T$ conditions of $0.7[\mathrm{GPa}]$ and $1000\left[{ }^{\circ} \mathrm{C}\right]$.

$\rho_{0}=$ density at room pressure $\left(P_{0}\right)$ and temperature $\left(T_{0}\right)$.

$K=$ bulk modulus in [GPa]: ol=126.3 (Abramson et al., 1997); opx=115.5 (Chai et al., 1997); $c p x=113.0$ (Levien et al., 1979).

$K^{\prime}=$ bulk modulus pressure derivatives: $\mathrm{ol}=4.28$; opx $=7.82 ; \mathrm{cpx}=4.80$; same authors.

$\alpha_{\mathrm{av}}=$ volume thermal expansion coefficient* in $\left[{ }^{\circ} \mathrm{C}^{-1}\right]$ : ol $=3.81 \cdot 10^{-5}$ (Hazen, 1976); opx $=3.45 \cdot 10^{-5}$ (Jackson et al., 2003); cpx $=4.10 \cdot 10^{-5}($ Finger and Ohashi, 1976).

$C_{\mathrm{ij}}(P, T)=$ elastic constants in $[\mathrm{GPa}]$ derived for $P / T$ conditions of $0.7[\mathrm{GPa}]$ and $1000\left[{ }^{\circ} \mathrm{C}\right]$.

$C_{\mathrm{ij}}\left(P_{0}, T_{0}\right)=$ elastic constants in [GPa] at room pressure and temperature for ol (Abramson et al., 1997), opx (Chai et al., 1997) and cpx (Collins and Brown, 1998).

$\mathrm{d} C_{\mathrm{ij}} / \mathrm{d} P=$ first order pressure derivatives (nondimensional) for ol (Abramson et al., 1997), opx (Frisillo and Barsch, 1972**) and cpx (Matsui and Busing, 1984***).

$\mathrm{d}^{2} C_{\mathrm{ij}} / \mathrm{d} P^{2}=$ second order pressure derivatives in $\left[\mathrm{GPa}^{-1}\right]$ for ol and opx; same authors.

$\mathrm{d} C_{\mathrm{ij}} / \mathrm{d} T=$ temperature derivatives in $\left[\mathrm{GPa} /{ }^{\circ} \mathrm{C}\right]$ for ol (Isaak, 1992), opx (Chai et al., 1997) and cpx (Frisillo and Barsch, 1972****).

* Average values considered constant over the temperature range of interest.

** Extrapolated to $1000\left[{ }^{\circ} \mathrm{C}\right]$, as suggested by Mainprice et al. $(2000)$.

*** Theoretical values.

**** Opx values were taken instead of the missing data for cpx, as recommended by Estey and Douglas (1986).

A purely random LPO gives a $J$ of 1 , whereas for a single crystal, the texture index tends towards infinity (in reality to about 270 due to the truncation in spherical harmonic calculations and the Gaussian used).

LPOs are plotted on lower hemisphere equal area nets displaying multiple of uniform distribution contouring. As Lanzarote xenoliths are often small in size (typically only a few $\mathrm{cm}$ ) and lack a clear macroscopic fabric, the geometric elements commonly used for the structural reference frame (foliation and lineation) were often not visible at the scale of hand specimen. This, added to the need for large areas of analysis, led us to choose the sample's orientation based on the shape of the hand specimen rather than on the textural parameters. All orientation data acquired on non-oriented samples were rotated after EBSD acquisition. Depending on the possibility or impossibility to determine the foliation plane in three dimensions (from grain shape in EBSD orientation maps and observation on perpendicular cuts of the sample block), two different rotation procedures were applied. (1) If the foliation could be identified, orientation data were rotated in order to place the foliation either horizontally, for the samples with a normal foliation ( $Z=$ pole of the normal foliation), or vertically for those with an anomalous foliation $(X=$ pole of the anomalous foliation). This setting is considered the most appropriate because it assumes that the original foliation, which should have developed contemporaneously with the LPO, was in horizontal position. This option also makes texture comparisons between samples 
a) [100]

[010]
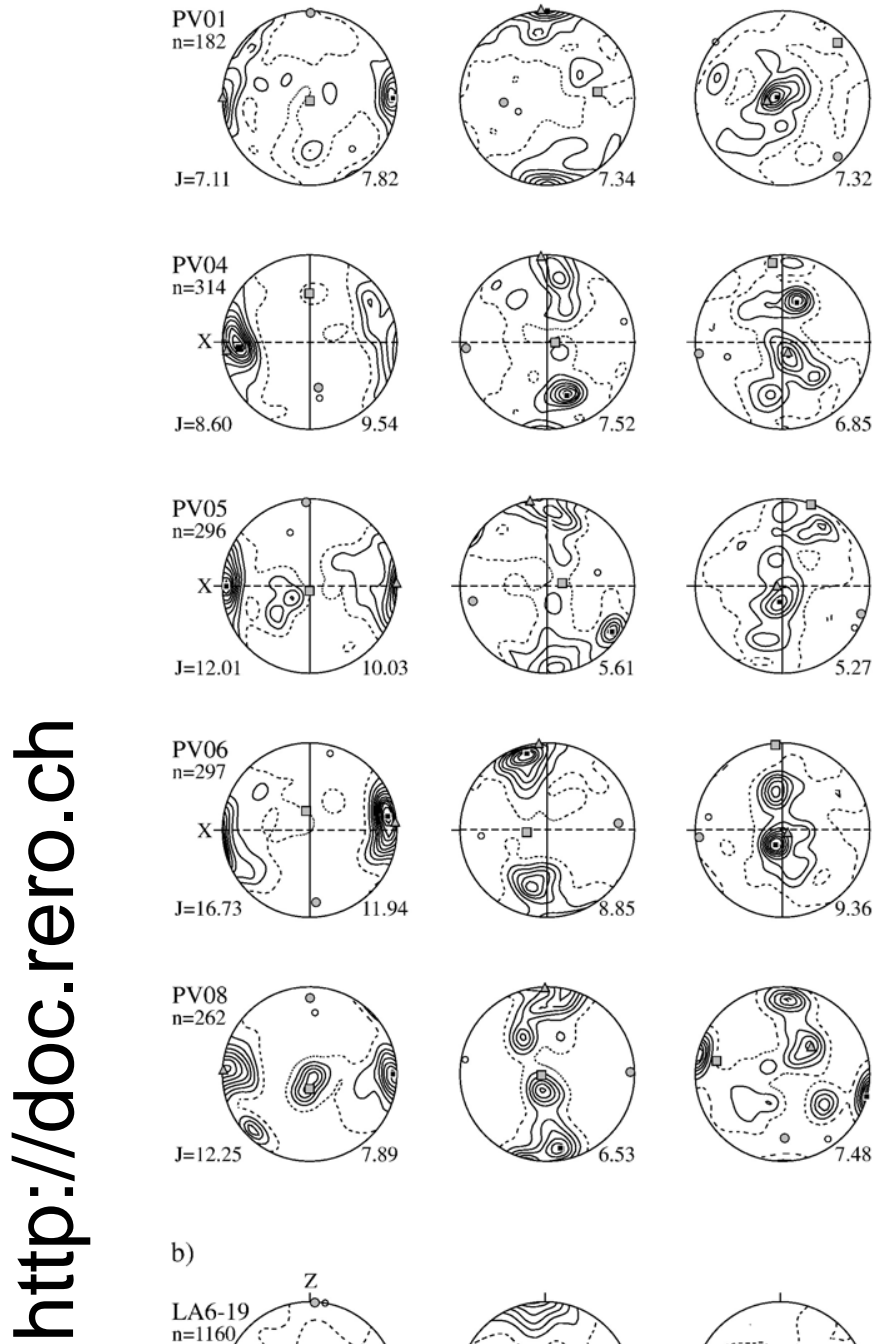
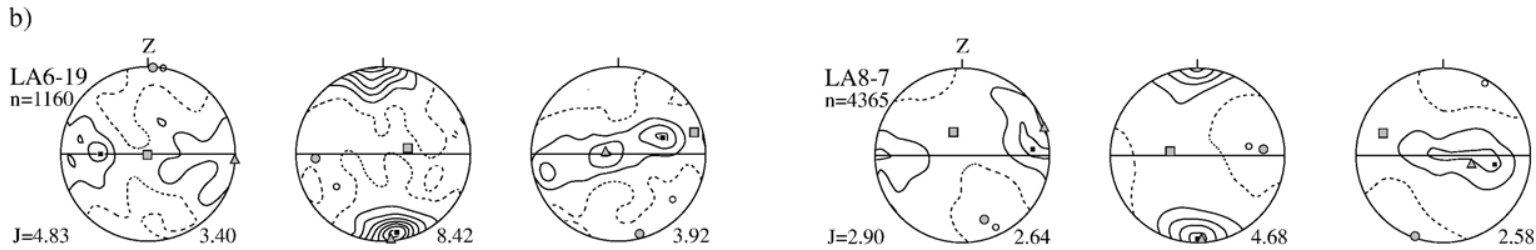

Fig. 5. Olivine pole figures showing the preferred orientations of the [100], [010] and [001] axes for the 12 Lanzarote xenoliths. LPOs of group I are shown in (a), those of group II in (b). Pole figures are represented on lower hemisphere equal area projections. When observed, foliation is represented by a continuous line either horizontally for the samples with a normal foliation ( $Z$ =pole of the normal foliation) or vertically for those with an anomalous foliation ( $X=$ pole of the anomalous foliation). For the latter, the approximate position of the original foliation is indicated by a dashed line. Samples lacking any visible foliation are oriented with the maximum alignment (eigenvectors) of olivine [100] and [010] to the left and to the top, respectively. In case of an asymmetric distribution of [100] axes relative to the pole maximum, the data were rotated so that the tails are counterclockwise from their maxima (assuming a dextral shear). Contours are multiples of uniform distribution ( 1 m.u.d. intervals) beginning at 0.5 (dashed line); the number on the bottom right of each plot expresses the maximum density (position marked by a small black square on pole figures) Labels on the left side of each plot row indicate sample number, approximate number of grains $n$ analyzed and texture index $J$. The three eigenvectors $e_{1}, e_{2}$ and $e_{3}$ are plotted as grey triangles, squares and discs, respectively.

with both normal and anomalous foliations possible. In texture and seismic plots, the visible foliation is indicated by continuous line, whereas the original foliation is approximated by a dashed line. As lineation was never observed in these samples, the orientation data were then rotated within the foliation plane assuming olivine [100] (for the samples with a normal foliation) or [010] (for those with anomalous foliation) pole maxima (eigenvectors) as lineation indicators placed in the projection plane towards $X$ or $Z$, respectively. (2) Orientation data 
of the samples, for which neither foliation nor lineation could be determined, were rotated so that olivine [100] and [010] pole maxima (eigenvectors) correspond to the $X$ and $Z$ structural directions, respectively. Previous authors (e.g. Ben Ismaïl and Mainprice, 1998; Mainprice et al., 2000) had also identified those directions with $X$ and $Z$ in oceanic upper mantle peridotites.

From the 12 Lanzarote xenoliths, an average sample LPO (e.g. Mainprice and Humbert, 1994; Ben Ismaïl and Mainprice, 1998, Pera et al., 2003) was calculated for olivine, orthopyroxene and clinopyroxene after rotation in the common reference frame. Averages were obtained by merging all the orientations of a given phase, each measurement having the same weight independently of the size of the scan. Pole figures for ortho- and clinopyroxene were calculated only for the total data set but not for the individual samples, as the number of grains per scan was too small to generate any representative texture.

\subsection{Calculation of seismic properties}

The density and elastic constants used for the determination of the seismic velocities from LPOs were extrapolated to a pressure of $0.7 \mathrm{GPa}$ and a temperature of $1000^{\circ} \mathrm{C}$ for the whole sample population (Table 2). These $P / T$ estimates were taken from the thermobarometric analyses of Neumann et al. (1995). As olivine showed little chemical variability from one sample to another (Fo ${ }_{89.7-92.1}$ on the samples analyzed by Neumann et al., 1995), the variation of density and elastic constants with iron content was not taken into account and a fixed composition of $\mathrm{Fo}_{90}$ was assumed for calculations.

The effective elastic constants of the samples were calculated using the Voigt average over all reliable crystal orientation measurements. For any propagation direction, the velocity of compressional $(\mathrm{Vp})$ and shear waves $\left(\mathrm{Vs}_{1}\right.$ and $\left.\mathrm{Vs}_{1}\right)$ is calculated. Anisotropy of $\mathrm{P}$-waves $(\mathrm{AVp})$ is defined by the relation $100 \%\left(\mathrm{Vp}_{\max }-\mathrm{Vp}_{\min }\right) /\left[1 / 2\left(\mathrm{Vp}_{\max }\right.\right.$ $\left.+\mathrm{V} \mathrm{p}_{\text {min }}\right)$ ], where $\mathrm{V} \mathrm{p}_{\max }$ and $\mathrm{V} \mathrm{p}_{\min }$ are the maximum and minimum P-wave velocity observed in a given sample, respectively. Calculations of S-wave anisotropy (AVs) are based on the velocities of the fast and slow S-wave members produced by shear wave splitting. For each given direction, $\mathrm{AVs}$ is determined using the relation $100 \%\left(\mathrm{Vs}_{1}-\mathrm{Vs}_{2}\right) /\left[1 / 2\left(\mathrm{Vs}_{1}+\mathrm{Vs}_{2}\right)\right]$, where $\mathrm{Vs}_{1}$ is the faster wave members and $\mathrm{Vs}_{2}$ the slower (Mainprice and Silver, 1993). Calculations were performed for each sample from the corresponding LPO, assuming a modal composition of $100 \%$ olivine. The seismic behavior of the peridotite average sample was determined based on olivine, orthopyroxene and clinopyroxene average sam- ple LPOs, assuming a composition of 84 vol.\% olivine, 14 vol.\% orthopyroxene and 2 vol.\% clinopyroxene.

\section{Results}

\subsection{Lattice preferred orientation (LPO)}

LPOs of olivine for each of the 12 xenoliths are presented in Fig. 5, whereas Fig. 6 shows the average sample LPOs for olivine, orthopyroxene and clinopyroxene.

LPO data of olivine can be divided in two groups. Group I (Fig. 5a) is characterized by a strong clustering of the [100] poles parallel to the $X$ structural direction. The distribution of [010] and [001] axes is less straightforward and ranges between two end members. At one end, [010] and [001] have clear but relatively weak maxima in the $Z$ and $Y$ directions, respectively. This LPO is commonly referred as single crystal texture and corresponds to the type A of Ben Ismail and Mainprice (1998). At the other end, [010] and [001] tend to form diffuse girdles in the $Y Z$ structural plane normal to the $X$ structural direction, with [100] acting as an approximate axis of rotational symmetry. Occasionally, secondary peaks appear within these girdles. This LPO was described as [100] fiber texture by Bunge (1982) and corresponds to the type B of Ben Ismail and Mainprice (1998). Since most of the samples of group I show an intermediate LPO between both end members, they have been attributed to a common textural entity in our study. The LPOs of

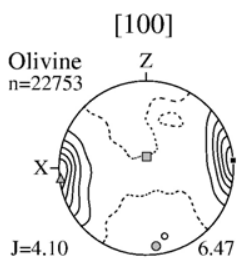

[010]
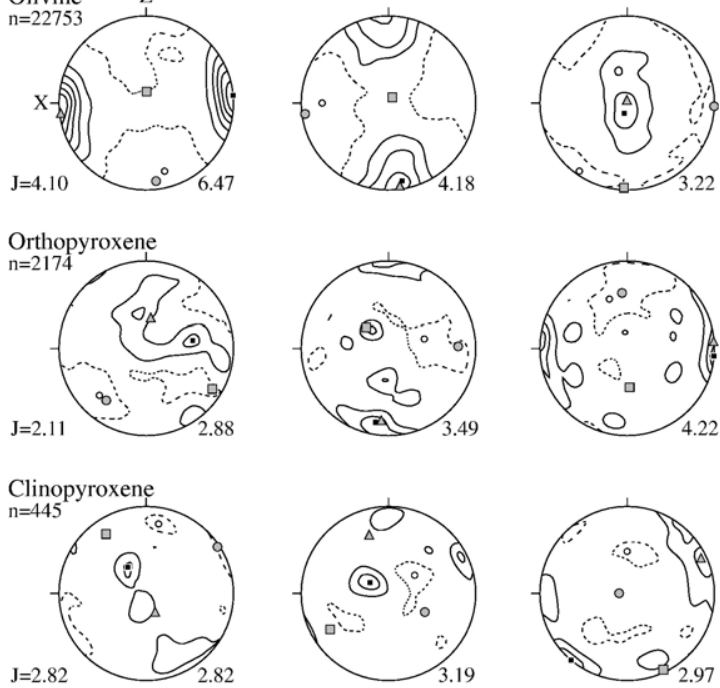

[001]
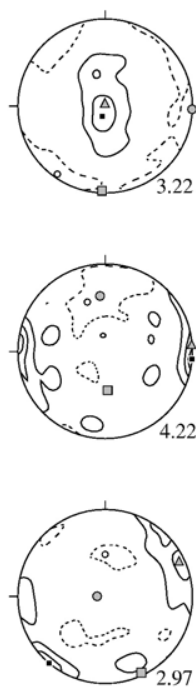

Fig. 6. Average sample LPOs of olivine, orthopyroxene and clinopyroxene plotted on lower hemisphere equal area nets. Symbols, references and calculation methods as in Fig. 5. 
group II (Fig. 5b) show a clustering of [010] poles parallel to the $Z$ structural direction, with [100] and [001] distributed along girdles in the $X Y$ structural plane. This
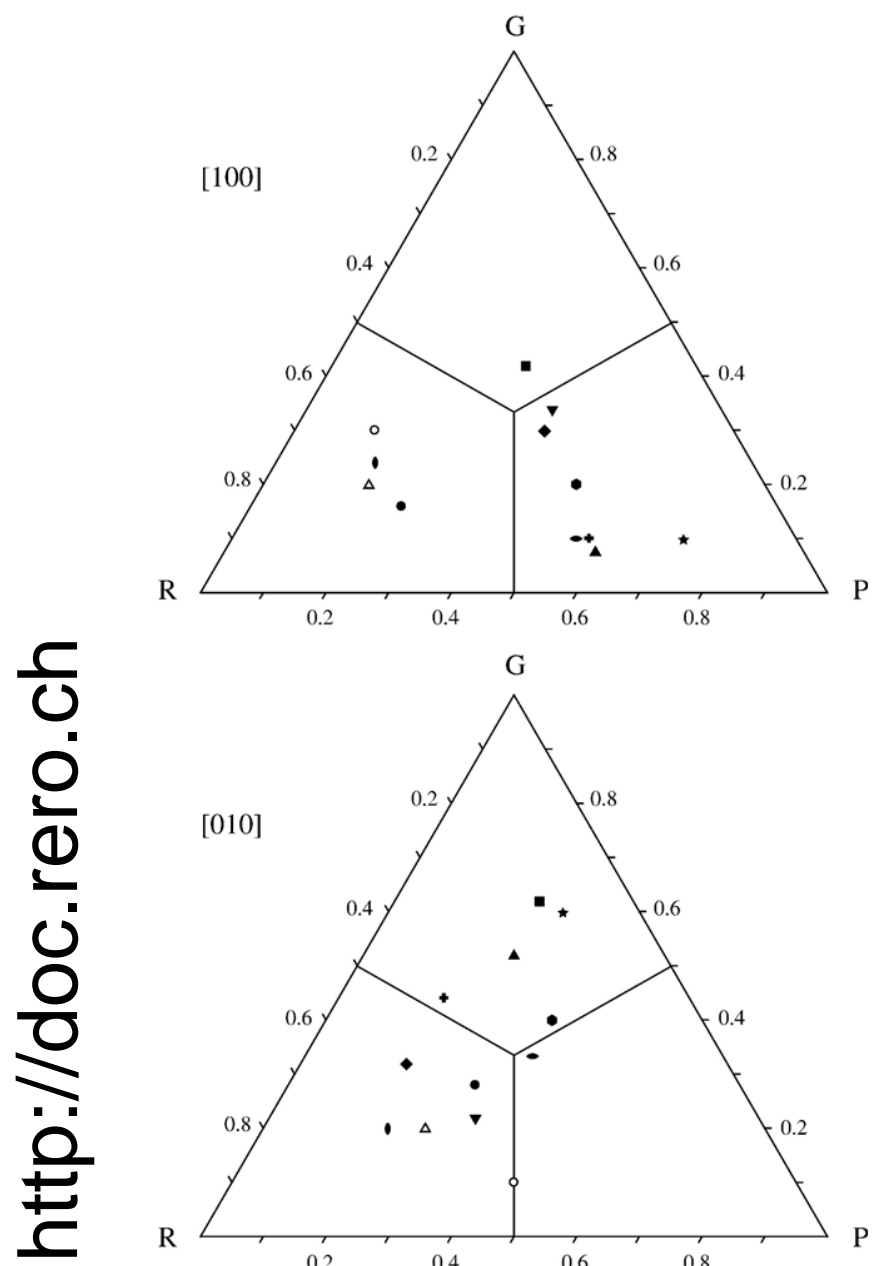
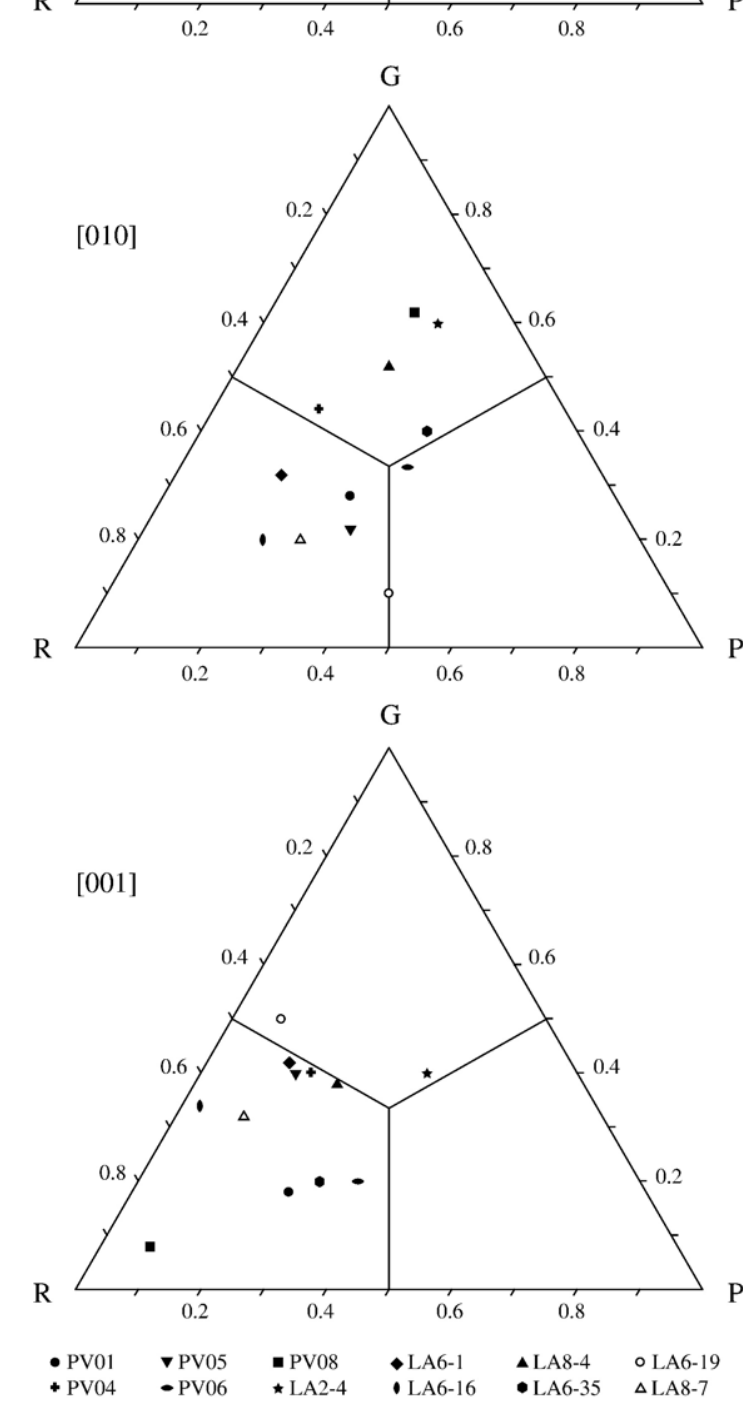

LPO is known as [010] fiber texture and was reported as type D in Ben Ismail and Mainprice's database. The texture index $J$ for olivine is comprised between 2.90 (LA8-7) and 16.73 (PV06). The olivine average sample is characterized by a texture index $J$ of 4.10 . As this average is strongly dominated by the samples of group I, it logically tends to the type A single crystal texture.

In order to analyze olivine pole figure symmetry in a more quantitative way, ternary PGR diagrams defined by point $(P)$, girdle $(G)$ and random $(R)$ apexes (Woodcock, 1977; Vollmer, 1990) were calculated from the three eigenvalues $\left(e_{1}, e_{2}\right.$ and $\left.e_{3}\right)$ of the [100], [010] and [001] distributions. The definitions of Vollmer (1990), with $P=e_{1}-e_{2}, G=2\left(e_{2}-e_{3}\right), R=3 e_{3}$ and $P+G+R=1$, were used for calculation. In the PGR diagrams (Fig. 7), the distribution of [100] matches fairly well the subdivisions put forward in the qualitative analysis, the samples of group I being mainly located in the $P$ domain, whereas those of group II are all in the $R$ field. Three samples of group I, however, depart from the rule: PV08, which develops a stronger girdle $(G)$ component due to a secondary maximum in the $X Y$ plane, as well as PV01 and LA6-16, which are maintained in the $R$ field of the diagram due to their weak [100] pole maxima. The distribution of [010] is more dispersed: samples of group I are mainly spread within the $R$ and $G$ fields, whereas both samples of group II, despite a stronger point $(P)$ component, do not cross the $R-P$ field boundary. Finally, nearly all samples plot in the $R$ field for [001], which reflects the large dispersion of maxima in [001] pole figures. The two samples of group II mark a trend towards the $G$ field.

LPO of the orthopyroxene average sample is characterized by several weakly clustered maxima. The fabric for [001] shows one single maximum very close to the $X$ structural direction, which is the normal feature commonly reported in the literature (e.g. Mainprice et al., 2000). Several weak [010] poles are observed in the $Y Z$ plane, whereas the maximum of the [100] pole distribution is asymmetric to the $X, Y$ and $Z$ tectonic orientations. The $J$ index for orthopyroxene average sample is 2.11 .

The LPO patterns of the clinopyroxene average sample display also a weak texture. The orientation distribution of the [001] axes shows a more pronounced obliquity than orthopyroxene relative to the $X$ structural direction. [010] poles have three maxima, the strongest being close to the $Y$ direction, whereas [100] axes

Fig. 7. PGR diagrams of olivine [100], [010] and [001] crystallographic axes calculated from eigenvalues $e_{1}, e_{2}$ and $e_{3}$ normalized to 1 , with $P=e_{1}-e_{2}, G=2\left(e_{2}-e_{3}\right), R=3 e_{3}$ and $P+G+R=1$. The majority of xenoliths fall in the $P$ domain for [100], in the $R$ or $G$ fields for [010] and in the $R$ domain for [001]. Samples of group I and II are represented by full and open symbols, respectively. 
distribution shows several very weak maxima oblique to the $Y Z$ plane. The texture index $J$ equals 2.82 .

\subsection{Seismic properties}

The projections of the calculated seismic properties of the xenoliths (Fig. 8), considering only the contribu- tion of olivine grains, display either an orthorhombic symmetry (PV01, PV05, PV06, PV08, LA6-1, LA6-16, LA6-19, LA6-35 and LA8-7) or tend to a transverse isotropic character with a symmetry axis parallel to $\mathrm{Vp}_{\max }$ (PV04, LA2-4 and LA8-4). V $\mathrm{p}_{\max }$ ranges from 8.29 to $9.01 \mathrm{~km} / \mathrm{s}\left(\mathrm{Vp}_{\text {mean }}=8.62 \mathrm{~km} / \mathrm{s}\right), \mathrm{Vs}_{1 \text { max }}$ from 4.69 to $4.92 \mathrm{~km} / \mathrm{s}\left(\mathrm{Vs}_{1 \text { mean }}=4.82 \mathrm{~km} / \mathrm{s}\right)$ and $\mathrm{Vs}_{2 \max }$ from
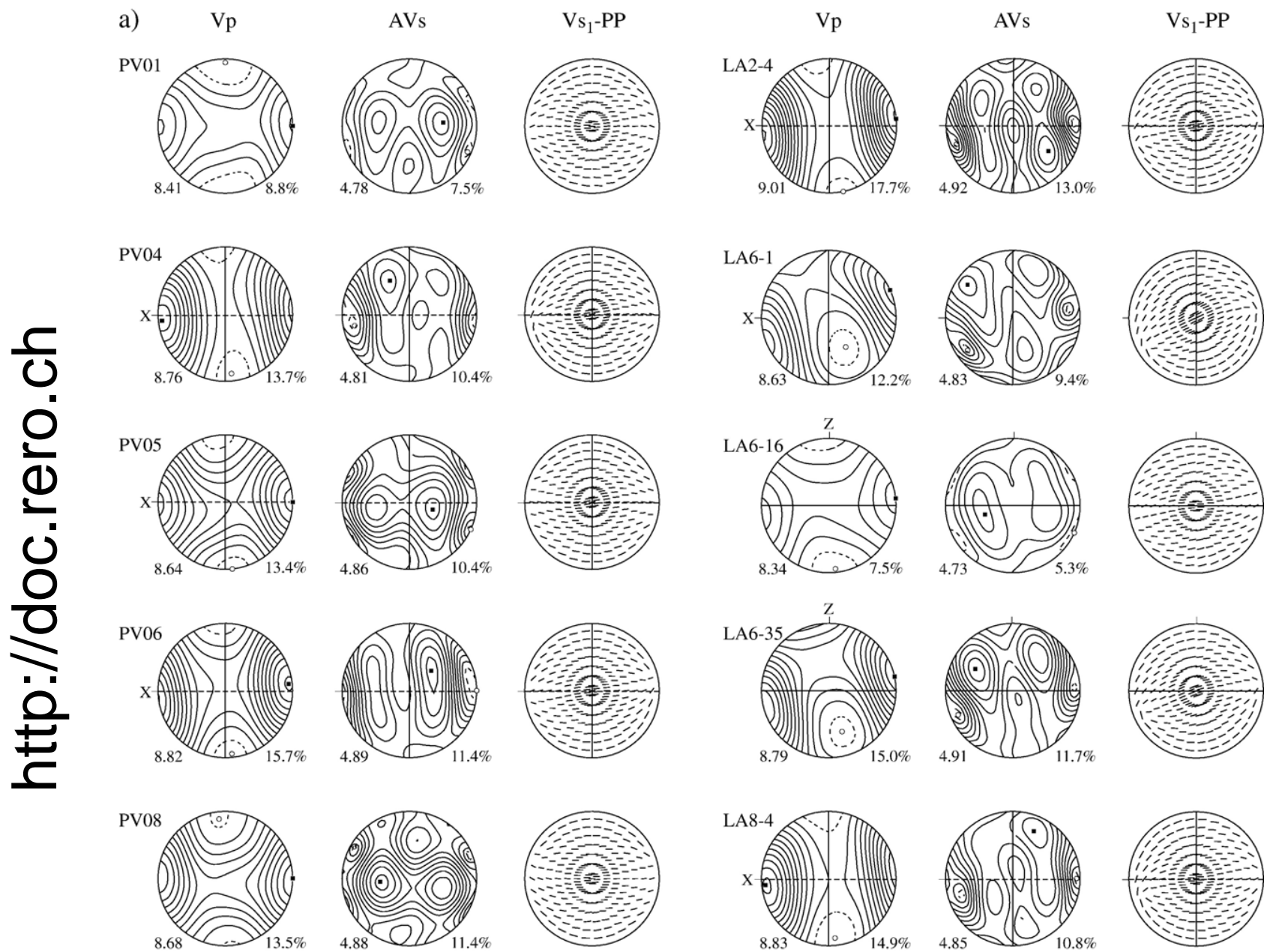

b)
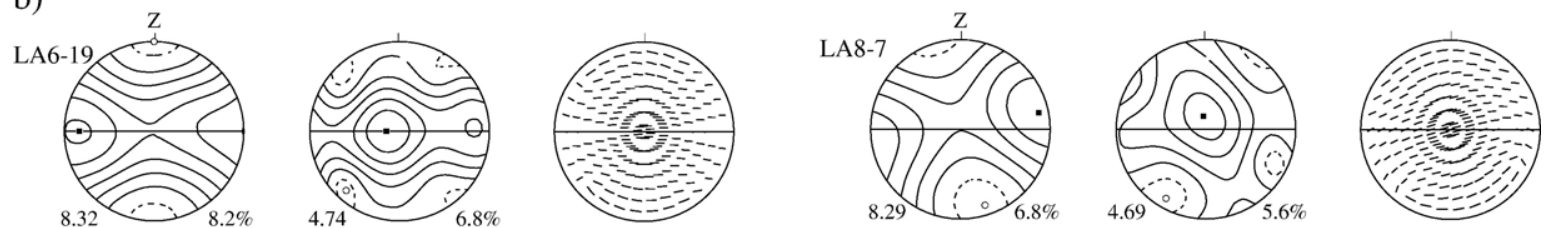

Fig. 8. Calculated seismic properties of the xenoliths using the LPO of Fig. 5 projected on lower hemisphere equal area nets. Column 1 (Vp) displays the velocity distribution of the P-waves $(0.1 \mathrm{~km} / \mathrm{s}$ intervals); the numbers right and left of the diagram show respectively the P-wave anisotropy (AVp) and the maximum velocity in $\mathrm{km} / \mathrm{s}$. Column 2 (AVs) shows the distribution of S-wave anisotropy (1\% contour intervals), resulting from shear wave splitting. Maximum anisotropy is presented at the bottom right and maximum $\mathrm{Vs}_{1}$ at the bottom left. For both Columns 1 and 2, the dashed line represents the minimum contour, and the directions corresponding to the maximum and minimum value in the plot are marked by solid square and open circle, respectively. Column $3\left(\mathrm{Vs}_{1}-\mathrm{PP}\right)$ exhibits the polarization plane of the faster S-wave. All calculations were performed using the Voigt average. $X$, $Y$ and $Z$ as in Fig. 5. 
4.56 to $4.63 \mathrm{~km} / \mathrm{s}\left(\mathrm{Vs}_{2 \text { mean }}=4.59 \mathrm{~km} / \mathrm{s}\right)$. The seismic anisotropy varies between 6.8 and $17.7 \%$ for $\mathrm{AVp}$ $\left(\mathrm{AVp}_{\text {mean }}=12.3 \%\right)$ and 5.3 to $13.0 \%$ for the maxima of AVs plots $\left(\mathrm{AVs}_{\text {mean }}=9.5 \%\right)$. When plotted versus fabric strength (Fig. 9), AVp is in good agreement with the results derived from the updated olivine database of Ben Ismail and Mainprice (1998).

The fastest propagation of P-waves generally corresponds to the $X$ structural direction ([100] pole maximum), whereas the slowest $\mathrm{P}$-waves tends to propagate along the $Z$ structural direction ([010] pole maximum). However, because of the slightly asymmetric character of LPOs and the commonly observed obliquity of the pole maxima with respect to the structural directions, some samples (e.g. LA6-1 and LA6-35) show a slight obliquity of their seismic maximum and minimum relative to $X$ and $Z$, respectively. The maximum anisotropy of S-waves has no clear preferred orientation and points variably to a direction intermediate between $X, Y$ and $Z$ reference axes. AVs maxima strictly parallel to the $Z$ tectonic axes have never been observed. In most samples, the $\mathrm{Vs}_{1}$ polarization plane is parallel or subparallel to the foliation plane perpendicular to $Z$. For a few samples, however, the $\mathrm{Vs}_{1}$ polarization plane is tilted around the $Y$ direction.

The projections of the seismic velocities of the olivine and the peridotite average samples have a clear orthorhombic symmetry (Fig. 10). Seismic velocities and anisotropy of the olivine average sample reach $8.62 \mathrm{~km} / \mathrm{s}$ $\left(\mathrm{Vp}_{\max }\right), 4.79 \mathrm{~km} / \mathrm{s}\left(\mathrm{Vs}_{1 \max }\right), 4.60 \mathrm{~km} / \mathrm{s}\left(\mathrm{Vs}_{2 \max }\right), 11.9 \%$ $(\mathrm{AVp})$ and $7.9 \%$ (AVs). The peridotite average sample has slightly lower velocities $\left(8.45 \mathrm{~km} / \mathrm{s}\right.$ for $\mathrm{Vp}_{\max }, 4.76 \mathrm{~km} / \mathrm{s}$ for $\mathrm{Vs}_{1 \max }$ and $4.59 \mathrm{~km} / \mathrm{s}$ for $\mathrm{Vs}_{2 \max }$ ), and seismic

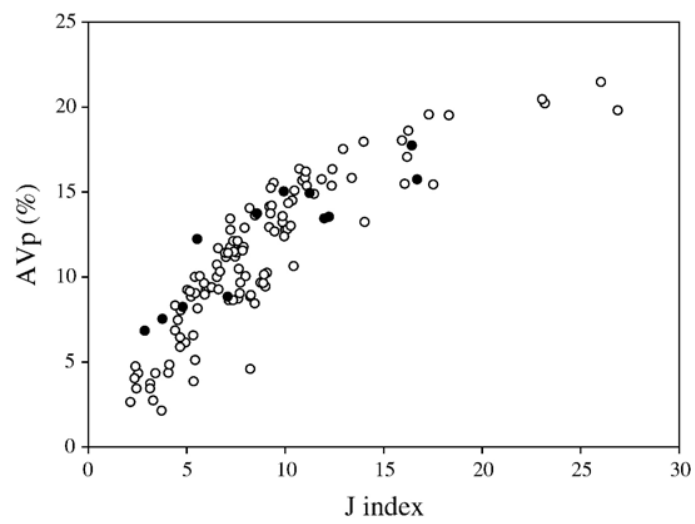

Fig. 9. Plot of fabric strength ( $J$ index) vs. anisotropy of P-waves $(\mathrm{AVp})$. The results for Lanzarote xenoliths (full circles) are compared with the updated olivine database (open circles) of Ben Ismaill and Mainprice (1998).
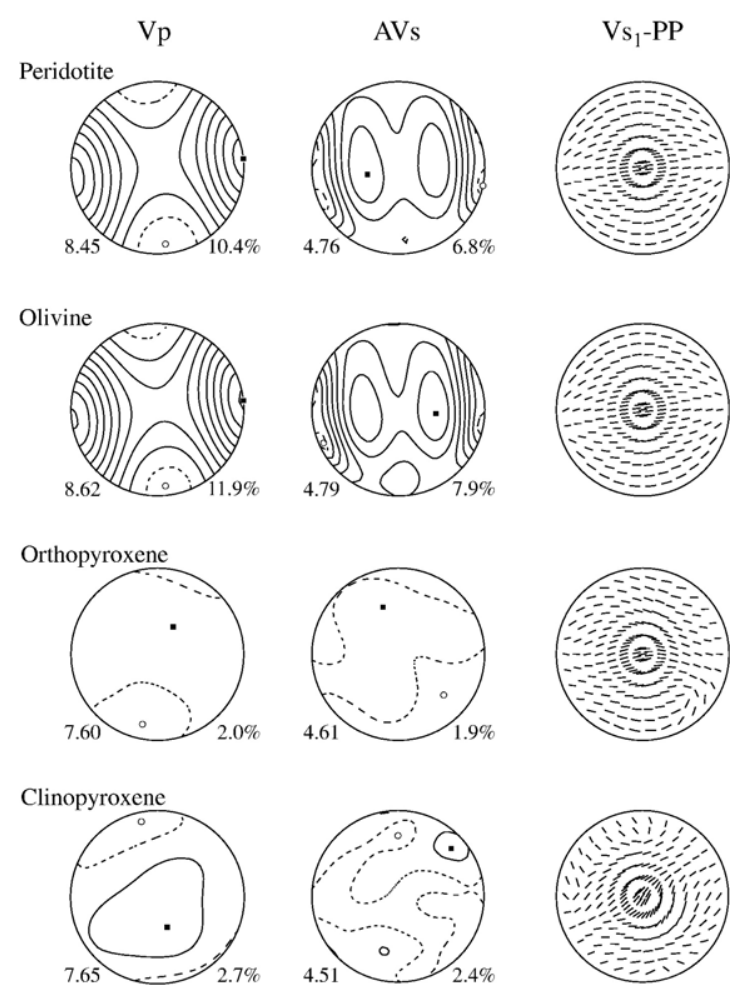

Fig. 10. Calculated seismic properties of the Lanzarote peridotite average sample (top), assuming a modal composition of 84 vol.\% olivine, 14 vol.\% orthopyroxene and 2 vol.\% clinopyroxene. Seismic properties of the olivine, orthopyroxene and clinopyroxene average samples are shown for comparison. Layout and reference frame as in Fig. 8 .

anisotropies (10.4\% for $\mathrm{AVp}$ and $6.8 \%$ for $\mathrm{AVs}$ ) than the olivine average sample. Orthopyroxene and clinopyroxene show very little anisotropy and lower absolute velocities compared to olivine.

\section{Discussion}

\subsection{Lattice preferred orientation}

Two groups of olivine LPO were distinguished in the ultramafic xenoliths of Lanzarote. Group I (10 samples) is represented by fabrics intermediate between the single crystal and the [100] fiber textures, whereas group II (2 samples) is approximated by the [010] fiber texture. These LPOs are typical of the upper mantle and have been widely reported in the literature (e.g. Brothers and Rodgers, 1969; Nicolas et al., 1973; Mercier and Nicolas, 1975; Christensen and Salisbury, 1979; Christensen, 1984; Mainprice and Silver, 1993; Ji et al., 1994; Ben Ismail and Mainprice, 1998; Mainprice et al., 2000). It is currently admitted that simple shear or a 

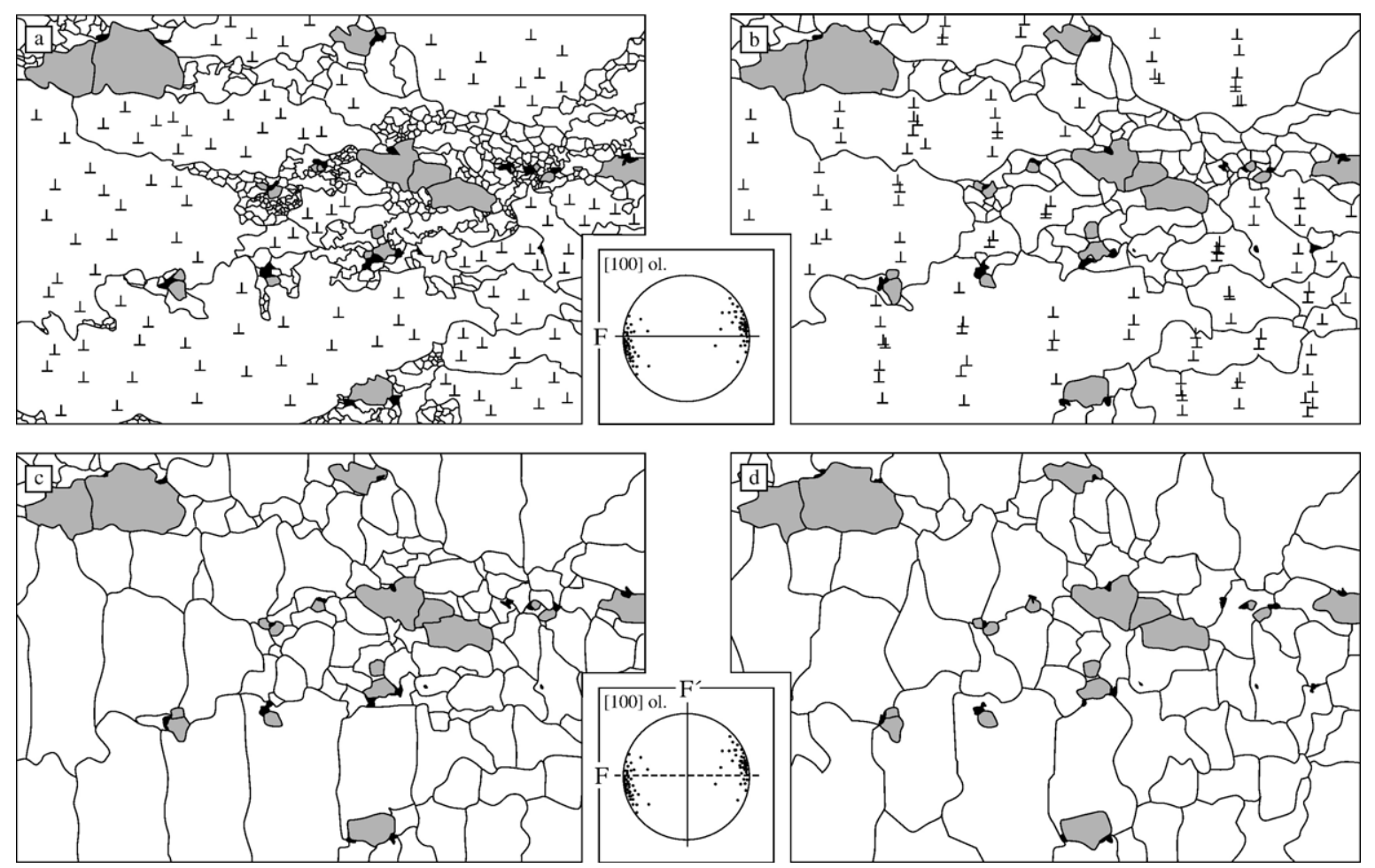

Fig. 11. Sketch illustrating the development of anomalous foliation in peridotite. Olivine grains are shown in white, pyroxene in grey and spinel in black; edge dislocations in large olivine porphyroclasts are indicated by $\perp$ symbols. (a) In response to stress (shear plane perpendicular, shear direction left-right), olivine has deformed through dislocation creep (mainly on the (010)[100] slip system), leading to a preferred orientation of the [100] axes close to the foliation F (trace marked by continuous line, top pole figure). (b) Reduction in free energy forces the dislocations to migrate to form well-developed and equally spaced subgrain boundaries. (c) When the difference in orientation across subgrain boundaries parallel to the (100) planes (normal to shear direction) becomes too large to be accommodated by dislocations, they evolve to grain boundaries. Depending on the spacing between the subgrain boundaries, the individual new grains may be elongated perpendicular to the original porphyroclasts. This marks a new foliation $\mathrm{F}^{\prime}$ (continuous line, bottom pole figure) normal to $\mathrm{F}$ (dashed line). As the overall olivine LPO is unaffected by this process, $\mathrm{F}^{\prime}$ appears now normal to the [100] axes of olivine. (d) Grain boundary migration and area reduction may further modify the microstructure leading to a possible weakening of the anomalous foliation with time. The presence of the original foliation $\mathrm{F}$ is sometimes suggested by the arrangement and shape of pyroxene and spinel grains, and above all by the completely unusual LPO of olivine at right angle to the visible foliation $\mathrm{F}^{\prime}$.

combination of simple and pure shear is the dominant deformation regime in the oceanic upper mantle (Nicolas, 1976). Generally, a simple shear component is indicated by a more or less pronounced obliquity of olivine [100] and [010] axes relative to the $X$ and $Z$ structural directions, respectively (Zhang and Karato, 1995). This characteristic is a common feature of the LPO in Lanzarote xenoliths. If we refer to the experimental deformation experiments of Tommasi et al. (1999) for polycrystalline olivine samples, the predominance of the single crystal and [100] fiber textures (group I) tends to indicate that low strain rate simple shear, with a possible tensional component (transtension), is the prevalent deformation regime for the source region of most of the Lanzarote xenoliths. These textures are consistent with the activation of the (010)[100] and (0kl)[100] slip systems at high to moderate operating temperatures (Raleigh, 1968; Carter and Avé Lallemant, 1970), in good agreement with the geothermometric determinations of Neumann et al. (1995). On the other hand, the occurrence of the [010] fiber texture (group II) is less common in the upper mantle. According to Tommasi et al. (1999), axial [010] LPO patterns with strong clustering of the [010] poles result either from widening-thinning shear (transpression) or axial shortening, the former being more likely in our xenoliths, due to the slight obliquity of the pole maxima. Whatever the scenario, the simultaneous occurrence of [100] and [010] fiber textures indicate that at least two deformation regimes operated at different locations in the upper mantle beneath Lanzarote, suggesting a different source location or depth for the xenoliths of groups I and II.

Ortho- and clinopyroxene display weaker LPOs. The larger bulk moduli of pyroxene relative to olivine require a higher stress to activate the dominant slip 
systems (Wenk and Bennet, 1991). In addition, as pyroxene represents only a small volume of the bulk composition, most of the strain is accommodated by the more ductile olivine matrix. Despite their weak textures, both ortho- and clinopyroxene show comparable orientations of the [001] maximum, i.e. slightly oblique to the $X$ structural direction in the $X Z$ plane. This preferred orientation is consistent with a deformation regime dominated by simple shear and compatible with the dominant dislocation glide direction in orthopyroxene (Coe and Kirby, 1975) and clinopyroxene (Van Roermund and Boland, 1981). In the samples characterized by an anomalous foliation ( $Y Z$ plane in texture plots), the orientation of the orthopyroxene [001] pole maximum close to the $X$ direction is an additional argument for our choice of reference frame.

\subsection{Anomalous foliation}

Anomalous foliations, with olivine [100] pole maximum oriented normal to the visible foliation
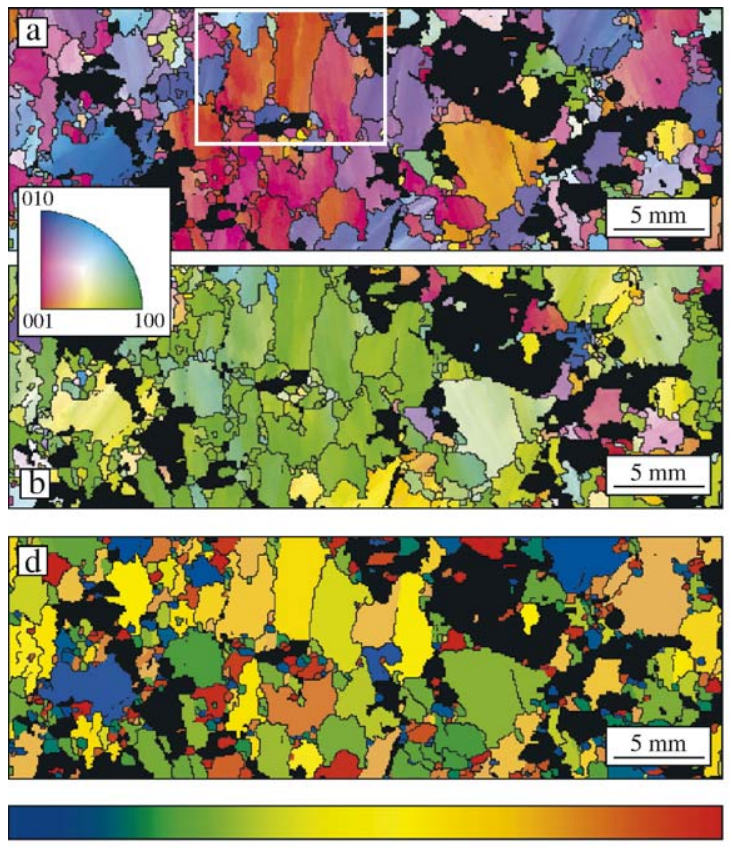

$0^{\circ}$ (Horizontal)

$90^{\circ}($ Vertical $)$

(Horizontal) $180^{\circ}$ plane, were observed in about half of the samples analyzed in this study. On the basis of microstructural (straight and parallel subgrain and grain boundaries) and crystallographic (similar lattice orientation of adjacent grains, orientation of orthopyroxene [001] maximum normal to the foliation) arguments, this feature is interpreted as a result of intensive recovery. The processes involved migration of edge dislocations on the (010)[100] glide system, development of widely spaced subgrain boundaries after alignment of dislocations, and individualization of new grains with a long axis at right angle to the primary foliation (Fig. 11). An example from our sample set is shown in Fig. 12.

It must be noted, however, that a right angle relationship between the foliation and the olivine [100] pole maxima is not necessarily the result of recovery processes. Jung and Karato (2001) showed experimentally that, in a water saturated system under high temperature and moderate stress, olivine [100] maxima can be orientated normal to the shear plane. The development of such patterns requires the activation of

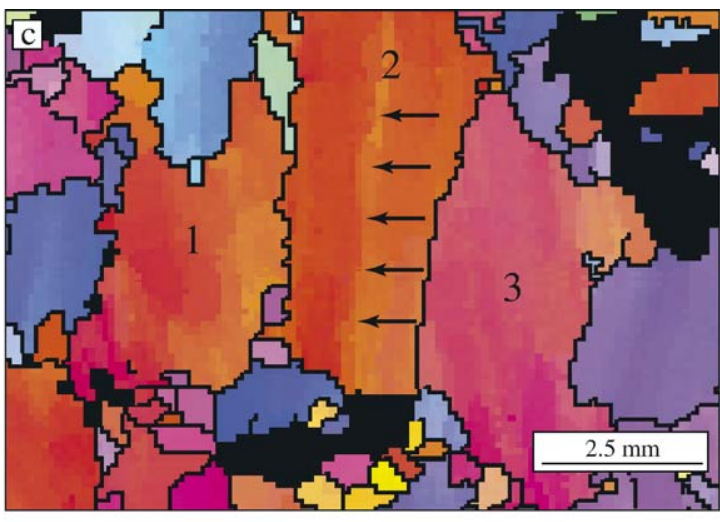

$\mathrm{e}$

[100]

[010]

[001]
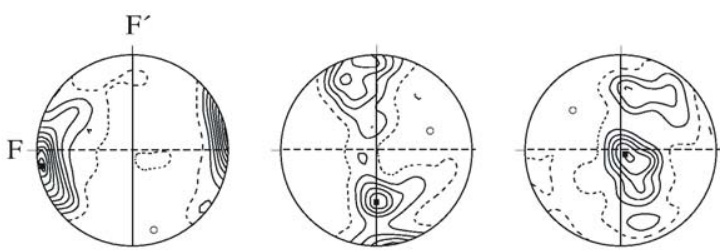

Fig. 12. Sample LA8-4 as an example with the anomalous foliation. Olivine inverse pole figure maps showing the crystallographic axes falling (a) parallel to the page normal (ND) and (b) parallel to the horizontal (TD). The recurrent greenish colors in (b) indicate that the [100] axis is preferentially oriented in horizontal position. Black are other minerals (opx, cpx and spinel). (c) Close-up view of the framed area in (a) showing three adjacent olivine grains with similar crystallographic orientation. These grains are separated by nearly straight grain boundaries, suggesting that they originally formed one single crystal with a long axis oriented horizontally. The vertical boundary separating two areas with different shades of red in grain 2 (arrows) suggests the development of a subgrain boundary. (d) Grain shape orientation map showing a weak preferred orientation of the larger olivine grains indicating a vertical alignment of their long axis (colors mainly range from pale green, yellow to salmon pink). (e) Olivine texture plot of the same sample with the visible foliation $\mathrm{F}^{\prime}$ (continuous line) and the approximate position of the original foliation $\mathrm{F}$ (dashed line). The location of [100] pole maximum relative to the actual foliation $\mathrm{F}^{\prime}$ coupled with the observations put forward in (a), (b), (c) and (d) strongly suggest that $\mathrm{F}^{\prime}$ is an anomalous foliation 


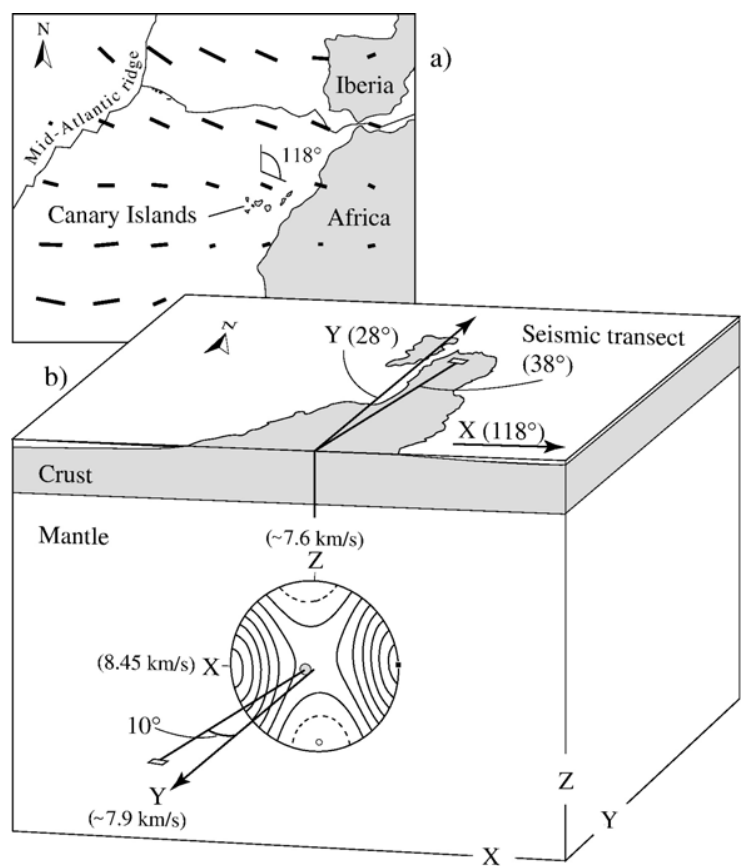

Fig. 13. (a) Sketch map showing the fastest wave propagation direction in the upper mantle below the Canary Islands according to Silveira et al. (1998). (b) Block diagram showing the orientation in space of the Pwave velocity plot of the peridotite average sample. The strike values for $X, Y$ and the seismic transect of Banda et al. (1981) are put in brackets. The calculated velocity of P-waves remains slightly below $7.9 \mathrm{~km} / \mathrm{s}$ for a strike of $38^{\circ}$, which is the direction of the seismic transect. As the direction of interest is close to the $Y$ direction, the velocity is only weakly influenced by any potential obliquity of the original texture.

the (100)[001] slip system, enabled by the fixation of hydroxyl groups in the olivine structure. Yet, this hypothesis seems very unlikely in our case for several reasons: (1) the source region of Lanzarote peridotites was described by Neumann et al. (2004) as a very depleted and only weakly metasomatized mantle, as evidenced by the absence of water bearing phases like phlogopite or amphibole. The patterns observed by Jung and Karato (2001), however, were from samples deformed under high water fugacity, comparable to the conditions found in mantle wedges above subduction zones. (2) In our samples, the orientations of subgrain boundaries perpendicular to the [100] axis clearly suggest a dislocation glide on the (010)[100] slip system (assuming edge dislocation). If plastic deformation had occurred according to the (100)[001] slip system, the subgrain boundaries would have been parallel to the [100] axis. (3) Finally, the patterns of Jung and Karato (2001) were extracted from fine grained experimental samples characterized by a very high degree of recrystallization. The samples from Lanzarote with a foliation normal to the olivine [100] maxima, however, display a completely different microstructure and grain size distribution, making a similar deformation path rather unlikely. Added to the initial observations, these arguments make recovery the most convincing explanation accounting for the occurrence of anomalous foliation in Lanzarote peridotites.

Maxima of olivine [100] perpendicular to the foliation were also reported in high pressure metaperidotites from Alpe Arami and Cima di Gagnone, Switzerland (Möckel, 1969; Frese et al., 2003). These peridotites, however, are considered to be from subduction zone upper mantle, where water fugacity and stress are sufficiently high to activate the (100)[001] slip system. The hypothesis of Jung and Karato (2001) is thus convenient in those cases.

\subsection{Comparison between measured and calculated velocities}

In a previous study, Banda et al. (1981) investigated the deep structure of Lanzarote using the seismic refraction method. Based on data collected on a NNESSW seismic transect, these authors suggested a depth of $11 \mathrm{~km}$ for the Moho and calculated a velocity of $7.4 \mathrm{~km} / \mathrm{s}$ for Pn-waves in the upper mantle. At the time, this very low mantle velocity was interpreted as a consequence of the anomalous character of the mantle close to the passive continental margin. Re-examining the record section of Banda et al. (1981), Dañobeitia and Canales (2000) proposed a depth of $18 \mathrm{~km}$ for the Moho and velocities of $7.6-7.8 \mathrm{~km} / \mathrm{s}$ for Pn-waves. They interpreted the interval between 11 and $18 \mathrm{~km}$ as underplated material. In order to compare the velocities extracted from the seismic survey with the present calculated values, the orientation relationship between the average sample seismic stereoplot and the seismic transect of Banda et al. (1981) needs to be established. Peridotite xenoliths provide no information on their original position and orientation in the mantle. However, helpful indications for the alignment of the stereoplot in space can be extracted from surface wave seismic investigations and tomography models.

A recent study (Gaherty, 2001), based on anomalous polarization anisotropies of Love-Rayleigh waves in the North Atlantic near Iceland, has suggested a vertical transport direction (lineation) in the first kilometers of the lithosphere. In this model, the olivine [100] maximum is vertical for rocks above $100 \mathrm{~km}$ depth, whereas a more classical horizontal position of lineation in the mantle is proposed for greater depths. It is 
suggested that the development of the vertical orientation was associated with the upwelling flow of the mantle below the Mid-Atlantic ridge, from which the fabric was preserved or "frozen" during the subsequent cooling of the lithosphere. This feature was observed not only in the immediate vicinity of the ridge, but also for progressively older lithospheric mantle $(>40 \mathrm{Ma})$, suggesting that no reorientation of the original fabric occurred in response to horizontal flow. It is not known whether such a vertical orientation is a general feature of the uppermost mantle in slow-spreading ridge systems, and whether it can be preserved unchanged at farther distance from the ridge, e.g. until beneath Lanzarote $(150 \mathrm{Ma})$. A vertical fabric preserved from the upwelling flow below the Mid-Atlantic ridge would tend to show a $X Y$ structural plane parallel to the ridge, favoring a fast wave propagation direction in the NNE-SSW direction when projected on the Earth surface.

However, if we refer to the anisotropy maps inferred from seismic tomography, the fastest propagation direction of Rayleigh waves (and thus also of P-waves) in the upper mantle beneath the Canary region is observed at a strike of about $118^{\circ}$ (Silveira et al., 1998), i.e. at about $90^{\circ}$ from the direction suggested by the model of Gaherty (2001). This result was obtained from measurements based on a $50 \mathrm{~s}$ wave period, which corresponds to an approximate depth of 75-100 km. Because of the shallower origin of our samples $(20-26 \mathrm{~km})$, this fastest wave propagation direction does not provide an irrefutable argument allowing our seismic stereoplot to be orientated in space. Nevertheless, it is inconsistent with a vertical fabric orientation of the upper mantle immediately above $100 \mathrm{~km}$ depth. The fastest propagation directions of Rayleigh waves inferred from other tomography models (e.g. Tanimoto and Anderson, 1985; Nataf et al., 1986; Montagner and Tanimoto, 1991) are consistent with the direction given by Silveira et al. (1998), but as they were deduced from waves in the $100-250 \mathrm{~s}$ period range (about $150-400 \mathrm{~km}$ ), they are less relevant for our purpose.

Further indications on the seismic properties of the uppermost mantle in the region were given by Contrucci et al. (2004), based on seismic reflection investigations carried out off the Moroccan coast. In their model, the Pn-wave velocity in the lithospheric mantle reaches 8.0 to $8.3 \mathrm{~km} / \mathrm{s}$ for a seismic transect oriented at a strike of $129^{\circ}$. Even if this record section is located about $500 \mathrm{~km}$ North-East of Lanzarote, the lithospheric crust in both places have the same age (Hinz et al., 1982; Roeser, 1982, Roest et al., 1992), thus making a comparison of mantle properties between both locations reasonable. The velocity obtained by Contrucci et al.
(2004) for a strike of $129^{\circ}$ is in good agreement with the fastest P-wave propagation direction of Silveira et al. (1998), pointing at a strike of $118^{\circ}$. This is a strong argument for the non-preservation of the potentially vertical fabric of the mantle (Gaherty, 2001) and its reorientation in response to horizontal flow (Blackman et al., 1996). Furthermore, it suggests a preservation of the fastest wave propagation direction from the asthenosphere to very shallow depth in the mantle.

On the basis of the above discussion, the seismic stereoplot of the peridotite average sample was orientated assuming a horizontal flow of the upper mantle and a fastest wave propagation direction corresponding to the strike mentioned by Silveira et al. (1998). As structural axes are orthogonal (with $Z$ vertical), $Y$ has a strike of $28^{\circ}\left(118^{\circ}-90^{\circ}\right)$. The original seismic transect of Banda et al. (1981) had a strike of approximately $38^{\circ}$, that is, at about $10^{\circ}$ from the $Y$ axis in the $X Y$ plane. When projected in the seismic stereoplot of our peridotite average sample, the direction of the seismic transect of Banda et al. (1981) corresponds to a velocity slightly smaller than $7.9 \mathrm{~km} / \mathrm{s}$ (Fig. 13). This value is in good agreement with the interpretation of Dañobeitia and Canales (2000), but much higher than the value of $7.4 \mathrm{~km} / \mathrm{s}$ put forward by Banda et al. (1981). Our results suggest that the velocity obtained by these latter authors is too low to be characteristic of the upper mantle, giving an additional argument for the presence of material different from the typical mantle rocks between 11 and $18 \mathrm{~km}$ in depth. Whether or not this material results from underplating (Dañobeitia and Canales, 2000) cannot be inferred from our study. The gabbroic xenoliths collected in Lanzarote by Schmincke et al. (1998) and Neumann et al. (2000), however, might give some indications on the nature of this zone. Finally, it must be noted that, whichever the orientation of the seismic stereoplot, our calculated velocities will always give higher values than the one suggested by Banda et al. (1981). This basically means that our conclusions relative to both field interpretations are independent on the correctness of the stereoplot orientation in space.

\subsection{Variations of calculated velocities due to $P / T$ estimates}

To check the validity of our argumentation relative to the wide range of pressure and temperature put forward by Neumann et al. (1995), the seismic velocity of the peridotite average sample was calculated for low $T /$ high $P$ and high $T /$ low $P$ end members, i.e. $800{ }^{\circ} \mathrm{C} / 0.8 \mathrm{GPa}$ and $1200{ }^{\circ} \mathrm{C} / 0.6 \mathrm{GPa}$, which corresponds to the highest 
and slowest seismic velocities. Even if these extreme intervals in $P / T$ conditions might have little geological significance with respect to the geothermal gradient, they give an idea of the possible error spread of calculated P-wave velocity. For $800{ }^{\circ} \mathrm{C}$ and $0.8 \mathrm{GPa}$, the seismic properties of $\mathrm{P}$-waves are the following: $\mathrm{Vp}_{\min }=7.73 \mathrm{~km} / \mathrm{s}, \mathrm{Vp}_{\max }=8.56 \mathrm{~km} / \mathrm{s}, \mathrm{AVp}=10.2 \%$, whereas for $1200{ }^{\circ} \mathrm{C}$ and $0.6 \mathrm{GPa}$, the calculations led to: $\mathrm{Vp}_{\min }=7.50 \mathrm{~km} / \mathrm{s}, \mathrm{Vp}_{\max }=8.34 \mathrm{~km} / \mathrm{s}, \mathrm{AVp}=10.6 \%$. Even if considering the latter interpretation as the true prevailing $P / T$ conditions in the lithospheric uppermost mantle beneath Lanzarote, the calculated seismic velocity in the transect direction of Banda et al. (1981), i.e. near $Y$, gives a value on the order of $7.75 \mathrm{~km} / \mathrm{s}$, i.e. far bigger than the velocity suggested from the original interpretation of those authors.

For a mantle lying at $11 \mathrm{~km}$ depth $(0.4 \mathrm{GPa})$, calculations show that a velocity of $7.4 \mathrm{~km} / \mathrm{s}$ in the direction of interest would require a tremendously high temperature without any geological significance. This makes the occurrence of other material type, e.g. mafic rocks, more convincing than mantle rocks in this depth range. The absence of mantle material between 11 and $18 \mathrm{~km}$ might also be suggested by the mineralogy of the samples with respect to the stability fields of peridotites. If mantle material would occur at such shallow depth, one would certainly expect to find a non-negligible amount of plagioclase-bearing peridotites in the xenolith population. On the contrary, plagioclase is absent in our sample set and occur only twice in minor amount in the whole sample population investigated by Neumann et al. (1995), thus giving an additional argument for a Moho lying at greater depth. In addition, serpentinization, which is often referred to as a possible explanation for the slowing down of seismic velocity in the upper mantle (e.g. Contrucci et al., 2004), was never observed in our samples and thus cannot account for the slow velocity of Banda et al. (1981). Lastly, in order to discard the possible influence of nonrepresentative sampling with respect to the true mantle fabric distribution, an average velocity for both porphyroclastic and protogranular samples was calculated separately for $800{ }^{\circ} \mathrm{C} / 0.8 \mathrm{GPa}$ and $1200{ }^{\circ} \mathrm{C} / 0.6 \mathrm{GPa}$ end members. A similar approach was performed considering successively samples of groups I and II, and finally assuming the same LPO types but for a single orientation ( $\mathrm{J}$ of 270). Even so, the calculated P-wave velocity was in all cases higher than $7.7 \mathrm{~km} / \mathrm{s}$ in the direction of interest, strongly suggesting that the observations put forward above are not due to bad sampling.

Finally, it must be noted that the slight velocity difference observed between the interpretation of
Dañobeitia and Canales (2000) and our calculated values might be due to several factors, some of them being inherent to the approach adopted here. This includes (1) the limitations to obtain a set of fully representative samples from the anisotropic uppermost mantle, (2) the presence of large olivine porphyroclasts, e.g. in sample LA2-4, which tend to strengthen the average LPO and related seismic anisotropy, (3) the use of the Voigt average for calculation of seismic properties, which gives for olivine values of about $2 \%$ higher than the Reuss averaging method and (4) the inaccurate knowledge of the $P / T$ conditions for the xenoliths source region, necessary to calculate the elastic constants at elevated pressure and temperature. In addition, melt occurrence in the upper mantle leads to a slight decrease of the measured velocity, thus increasing the gap between velocities obtained from seismic transects and values calculated from texture data (e.g. Hess, 1964; Kern et al., 1996).

\section{Conclusions}

In this paper, a petrophysical analysis of the ultramafic xenoliths of Lanzarote was presented. From the measured LPOs, the seismic velocities in their anisotropic distribution were calculated and compared to the existing geophysical interpretations. The main points of interest are summarized below.

(1) Lanzarote xenoliths exhibit two types of olivine preferred orientation. The first texture group showed a clustering of the [100] axis around the $X$ direction, with fabrics intermediate between the single crystal and [100] fiber textures, whereas the second displayed a [010] fiber texture, with strong clustering of the [010] axes around the $Z$ direction. The simultaneous occurrence of both textural groups suggests the coexistence of two different deformation regimes, probably dominated by a simple shear component under low strain rate and moderate to high temperature.

(2) Strong recovery processes led to the development of an anomalous foliation, with the olivine [100] maximum oriented perpendicular to the visible foliation. The possibility that this feature resulted from deformation in a water-rich environment was ruled out on the basis of microstructural, crystallographic and geochemical evidence.

(3) Velocities of P-waves calculated from the peridotite average sample range from $7.62 \mathrm{~km} / \mathrm{s}$ to $8.45 \mathrm{~km} / \mathrm{s}$. The value slightly smaller than $7.9 \mathrm{~km} / \mathrm{s}$, obtained in the direction of the seismic transect of Banda et al. (1981), is in good agreement with the latest interpretation of Dañobeitia and Canales (2000). Our results are consistent 
with a roughly $\mathrm{W}-\mathrm{E}$ oriented fastest wave propagation direction and an original foliation in horizontal position.

(4) Average sample calculations performed separately for varied $P / T$ conditions, as well as for each fabric types, suggest that our interpretations are robust, even if errors in $P / T$ estimates and truly representative sampling are considered.

\section{Acknowledgments}

The authors thank David Mainprice for his constructive remarks related to texture analysis and the free disposal of the Unicef Careware software package. A special thanks is addressed to Andréa Tommasi for the enthusiastic welcome in the Montpellier laboratory and her perspicacious comments on our microstructures. We are also very grateful to ElseRagnhild Neumann for providing seven fresh xenoliths from Lanzarote, to the Timanfaya National Park administration for authorizing the field work and to Fiona Gore for reviewing the linguistic aspects of the manuscript. Finally, we appreciate the work of JeanPaul Bourqui, Christoph Neururer and René Vonlanthen who lent an extremely valuable technical support during this study.

\section{References}

Abdel Monem, A., Watkins, N.D., Gast, P.W., 1971. Potassium-argon ages, volcanic stratigraphy, and geomagnetic polarity history of the Canary Islands: Lanzarote, Fuerteventura, Gran Canaria, La Gomera. American Journal of Science 271, 490-521.

Abramson, E.H., Brown, J.M., Slutsky, L.J., Zaug, J., 1997. The elastic constants of San Carlos olivine to $17 \mathrm{GPa}$. Journal of Geophysical Research 102, 12253-12263.

Adams, B.L., Wright, S.I., Kunze, K., 1993. Orientation imaging: the emergence of a new microscopy. Metallurgical Transactions. A, Physical Metallurgy and Materials Science 24, 819-831.

Allègre, C.J., Hamelin, B., Dupré, B., 1984. Statistical analysis of isotopic ratios in MORB: the mantle blob cluster and the convective regime of the mantle. Earth and Planetary Science Letters 71, 71-84.

Anguita, F., Hernán, F., 1975. A propagating fracture model versus a hot spot in the Canary Islands. Earth and Planetary Science Letters 27, 11-19.

Anguita, F., Hernán, F., 2000. The Canary Islands origin: a unifying model. Journal of Volcanology and Geothermal Research 103, 1-26.

Araña, V., Ortiz, R., 1986. Marco geodinámico del volcanismo canario. Anales de Física 82, 202-231.

Banda, E., Dañobeitia, J.J., Suriñach, E., Ansorge, J., 1981. Features of crustal structure under the Canary Islands. Earth and Planetary Science Letters 55, 11-24.

Barruol, G., Kern, H., 1996. Seismic anisotropy and shear-wave splitting in the lower-crustal and upper-mantle rocks from the Ivrea Zone - Experimental and calculated data. Physics of the Earth and Planetary Interiors 95, 175-194.
Ben Ismaill, W., Mainprice, D., 1998. An olivine fabric database: an overview of upper mantle fabrics and seismic anisotropy. Tectonophysics 296, 145-157.

Blackman, D.K., Kendall, J.M., Dawson, P.R., Wenk, H.R., Boyce, D., Morgan, J.P., 1996. Teleseismic imaging of subaxial flow at midocean ridges: travel time effects of anisotropic mineral texture in the mantle. Geophysical Journal International 127, 415-426.

Bosshard, E., MacFarlane, D.J., 1970. Crustal structure of the western Canary Islands from seismic refraction and gravity data. Journal of Geophysical Research 75, 4901-4918.

Boullier, A.M., Nicolas, A., 1975. Classification of textures and fabrics of peridotites xenoliths from South African kimberlites. Physics and Chemistry of the Earth 9, 467-475.

Brothers, R.N., Rodgers, K.A., 1969. Petrofabric studies of ultramafic nodules from Auckland, New Zealand. Journal of Geology 77, 452-465.

Bunge, H.J., 1982. Texture Analysis in Materials Science. Butterworth, London. 559 pp.

Burke, K., Wilson, J.T., 1972. Is the African plate stationary? Nature 239, 387-390.

Bystricky, M., Kunze, K., Burlini, L., Burg, J.P., 2000. High shear strain of olivine aggregates: rheological and seismic consequences. Science 290, 1564-1567.

Camacho, A.G., Vieira, R., 1991. Gravimetric study of Lanzarote island. Cahiers du Centre Européen de Géodynamique et de Séismologie 4, 339-351.

Carracedo, J.C., Day, S., Guillou, H., Rodríguez Badiola, E., Canas, J.A., Pérez Torrado, F.J., 1998. Hotspot volcanism close to a passive continental margin: the Canary Islands. Geological Magazine 135, 591-604.

Carter, C.B., Avé Lallemant, H.G., 1970. High temperature flow of dunite and peridotite. Geological Society of America Bulletin 81, 2181-2202.

Chai, M., Brown, J.M., Slutsky, L.J., 1997. The elastic constants of an aluminous orthopyroxene to $12.5 \mathrm{GPa}$. Journal of Geophysical Research 102, 14779-14785.

Chopra, P.N., Paterson, M.S., 1981. The experimental deformation of dunite. Tectonophysics 78, 453-473.

Christensen, N.I., 1984. The magnitude, symmetry and origin of upper mantle anisotropy based of fabric analyses of ultramafic tectonites. Geophysical Journal of the Royal Astronomical Society 76, 89-111.

Christensen, N.I., Salisbury, M.H., 1979. Seismic anisotropy of the oceanic upper mantle: evidence from the Bay of Islands Ophiolite Complex. Journal of Geophysical Research 84, 4601-4610.

Coe, R.S., Kirby, S.H., 1975. The orthoenstatite to clinoenstatite transformation by shearing and reversion by annealing: mechanism and potential applications. Contributions to Mineralogy and Petrology 52, 29-55.

Coello, J., Cantagrel, J.M., Hernán, F., Fúster, J.M., Ibarrola, E., Ancochea, E., Casquet, C., Jamond, C., Díaz de Téran, J.R., Cendrero, A., 1992. Evolution of the eastern volcanic ridge of the Canary Islands based on new $\mathrm{K}-\mathrm{Ar}$ data. Journal of Volcanology and Geothermal Research 53, 251-274.

Coisy, P., 1977. Structure et chimisme des péridotites en enclaves dans les basaltes du Massif central. Modèles géodynamiques du manteau supérieur. PhD Thesis, Nantes, 115 pp.

Collins, M.D., Brown, J.M., 1998. Elasticity of an upper mantle clinopyroxene. Physics and Chemistry of Minerals 26, 7-13.

Contrucci, I., Klingelhöfer, F., Perrot, J., Bartolome, R., Gutscher, M.A., Sahabi, M., Malod, J., Rehault, J.P., 2004. The crustal structure of the NW Moroccan continental margin from wide- 
angle and reflection seismic data. Geophysical Journal International 159, 117-128.

Dañobeitia, J.J., Canales, J.P., 2000. Magmatic underplating in the Canary Archipelago. Journal of Volcanology and Geothermal Research 103, 27-41.

Dash, B.P., Bosshard, E., 1969. Seismic and gravity investigations around the western Canary Islands. Earth and Planetary Science Letters 7, 169-177.

Estey, L.H., Douglas, B.J., 1986. Upper mantle anisotropy: a preliminary model. Journal of Geophysical Research 91, 11393-11406.

Finger, L.W., Ohashi, Y., 1976. The thermal expansion of diopside to $800{ }^{\circ} \mathrm{C}$ and a refinement of the crystal structure at $700{ }^{\circ} \mathrm{C}$. American Mineralogist 61, 303-310.

Forsyth, D.W., 1975. The early structural evolution and anisotropy of the oceanic upper mantle. Geophysical Journal of the Royal Astronomical Society 43, 103-162.

Frese, K., Trommsdorff, V., Kunze, K., 2003. Olivine [100] normal to foliation: lattice preferred orientation in prograde garnet peridotite formed at high $\mathrm{H}_{2} \mathrm{O}$ activity, Cima di Gagnone (Central Alps). Contributions to Mineralogy and Petrology 145, 76-85.

Frisillo, A.L., Barsch, G.R., 1972. Measurement of single-crystal elastic constants of bronzite as a function of pressure and temperature. Journal of Geophysical Research 77, 6360-6385.

Fúster, J.M., 1975. Las Islas Canarias: un ejemplo de evolución temporal y especial del vulcanismo oceánico. Estudios Geologicos 31, 439-463.

Fúster, J.M., Aguilar, M., 1965. Nota brevia sobre la geología del macizo de Betancuria, Fuerteventura. Estudios Geologicos 21, 181-198.

Fúster, J.M., Fernandez Santin, S., Sagredo, J., 1968. Geology and Volcanology of the Canary Islands, Lanzarote. Instituto Lucas Mallada, Madrid. $177 \mathrm{pp}$.

Gaherty, J.B., 2001. Seismic evidence for hotspot-induced buoyant flow beneath the Reykjanes Ridge. Science 293, 1645-1647.

Grunau, H.R., Lehner, P., Cleintuar, M.R., Allenbach, P., Bakker, G., 1975. New radiometric ages and seismic data from Fuerteventura (Canary Islands), Maio (Cape Verde Islands), and Sao Tomé (Gulf of Guinea). Progress in Geodynamics. R. Soc. Neth. Acad. Arts Sci., pp. 90-108.

Hazen, R.M., 1976. Effects of temperature and pressure on the crystal structure of forsterite. American Mineralogist 61, 1280-1293.

Hess, H.H., 1964. Seismic anisotropy of the uppermost mantle under oceans. Nature 203, 629-631.

Hinz, K., Dostmann, H., Fritsch, J., 1982. The continental margin of Morocco: seismic sequences, structural elements and geological development. In: Von Rad, U., Hinz, K., Sarnthein, M., Seibold, E. (Eds.), Geology of the Northwest African Continental Margin. Springer Verlag, Berlin, pp. 34-59.

Hoernle, K., Schmincke, H.U., 1993. The role of partial melting in the 15-Ma geochemical evolution of Gran Canaria: a blob model for the Canary Hotspot. Journal of Petrology 34, 599-626.

Hoernle, K., Zhang, Y.S., Graham, D., 1995. Seismic and geochemical evidence for large-scale mantle upwelling beneath the eastern Atlantic and western and central Europe. Nature 374, 34-39.

Holik, J.S., Rabinowitz, P.D., Austin, J.A., 1991. Effects of Canary hotspot volcanism on structure of oceanic crust off Morocco. Journal of Geophysical Research 96, 12039-12067.

Isaak, D.G., 1992. High-temperature elasticity of iron-bearing olivine. Journal of Geophysical Research 97, 1871-1885.

Jackson, J.M., Palko, J.W., Andrault, J.W., Sinogeikin, S.V., Lakshtanov, D.L., Wang, J., Bass, J.D., Zha, C.S., 2003. Thermal expansion of natural orthoenstatite to $1473 \mathrm{~K}$. European Journal of Mineralogy 15, 469-473.

Ji, S.C., Zhao, X.O., Francis, D., 1994. Calibration of shear-wave splitting in the subcontinental upper-mantle beneath active orogenic belts using ultramafic xenoliths from the Canadian Cordillera and Alaska. Tectonophysics 239, 1-27.

Jung, H., Karato, S.I., 2001. Water-induced fabric transitions in olivine. Science 293, 1460-1463.

Kern, H., Burlini, L., Ashchepkov, I.V., 1996. Fabric-related seismic anisotropy in upper-mantle xenoliths: evidence from measurements and calculations. Physics of the Earth and Planetary Interiors 95, 195-209.

Khan, M.A., 1974. Dynamic implications of mantle hotspots. Nature 251, 596-597.

Kumazawa, M., Anderson, O.L., 1969. Elastic moduli, pressure derivatives, and temperature derivatives of single-crystal olivine and single crystal forsterite. Journal of Geophysical Research 74, 5961-5972.

Kunze, F., Avé Lallemant, H.G., 1981. Non-coaxial experimental deformation of olivine. Tectonophysics 74, T1-T13.

Le Bas, M.J., Rex, D.C., Stillman, C.J., 1986. The Early magmatic chronology of Fuerteventura, Canary Islands. Geological Magazine 123, 287-298.

Le Pichon, X., Fox, P.J., 1971. Marginal offsets, fracture zones and the early opening of the North Atlantic. Journal of Geophysical Research 76, 6294-6308.

Levien, L., Weidner, D.J., Prewitt, C.T., 1979. Elasticity of diopside. Physics and Chemistry of Minerals 4, 105-113.

MacFarlane, D.J., Ridley, W.I., 1969. An interpretation of gravity data for Lanzarote, Canary Islands. Earth and Planetary Science Letters 6, 431-436.

Mainprice, D., 1999. The Unicef Careware software package. http:// www.isteem.univ-montp2/fr/TECTONOPHY/.

Mainprice, D., Silver, P.G., 1993. Interpretation of SKS-waves using samples from the subcontinental lithosphere. Physics of the Earth and Planetary Interiors 78, 257-280.

Mainprice, D., Humbert, M., 1994. Methods of calculating petrophysical properties from lattice preferred orientation data. Surveys in Geophysics 15, 575-592.

Mainprice, D., Ben Ismaill, W., Wagner, F., 1998. The relationship between olivine textures and seismic anisotropy in a database of upper mantle rocks. Materials Science Forum 273, 681-686.

Mainprice, D., Barruol, G., Ben Ismaill, W., 2000. The seismic anisotropy of the Earth's mantle: from single crystal to polycrystal. In: Karato, S.I., Forte, A.M., Liebermann, R.C., Masters, G., Stixrude, L. (Eds.), Earth's Deep Interior: Mineral Physics and Tomography from the Atomic to the Global Scale. AGU, Washington, pp. 237-264.

Marinoni, L., Pasquaré, G., 1994. Tectonic evolution of the emergent part of a volcanic ocean island: Lanzarote, Canary Islands. Tectonophysics 239, 111-137.

Matsui, M., Busing, W.R., 1984. Calculation of the elastic constants and high-pressure properties of diopside, $\mathrm{CaMgSi}_{2} \mathrm{O}_{6}$. American Mineralogist 69, 1090-1095.

Mercier, J.C., 1979. Peridotites xenoliths and the dynamic of kimberlite intrusion. In: Boyd, F.R., Meyer, H.O.A. (Eds.), The Mantle Sample, Inclusions in Kimberlites and Other Volcanics. American Geophysical Union, Washington, pp. 197-212.

Mercier, J.C., Nicolas, A., 1975. Textures and fabrics of upper-mantle peridotites as illustrated by xenoliths from basalts. Journal of Petrology 16, 454-487. 
Möckel, J.R., 1969. Structural petrology of the garnet peridotite of Alpe Arami (Ticino, Switzerland). Leidse Geologische Mededelingen 42, 61-130.

Montagner, J.P., Tanimoto, T., 1990. Global anisotropy in the upper mantle inferred from the regionalization of phase velocities. Journal of Geophysical Research 95, 4797-4819.

Montagner, J.P., Tanimoto, T., 1991. Global upper mantle tomography of seismic velocities and anisotropies. Journal of Geophysical Research 96, 20337-20351.

Morgan, W.J., 1971. Convection plume in the lower mantle. Nature 230, $42-44$.

Morgan, W.J., 1983. Hotspot tracks and the early rifting of the Atlantic. Tectonophysics 94, 123-139.

Nataf, H.C., Nakanishi, I., Anderson, D.L., 1984. Anisotropy and shear-velocity heterogeneities in the upper mantle. Geophysical Research Letters 11, 109-112.

Nataf, H.C., Nakanishi, I., Anderson, D.L., 1986. Measurements of mantle wave velocities and inversion for lateral heterogeneities and anisotropy. Journal of Geophysical Research 91, 7261-7307.

Neumann, E.R., Wulff Pedersen, E., Johnsen, K., Andersen, T., Krogh, E., 1995. Petrogenesis of spinel harzburgite and dunite suite xenoliths from Lanzarote, eastern Canary Islands: implication for the upper mantle. Lithos 35, 83-107.

Neumann, E.R., Sorensen, V.B., Simonsen, S.L., Johnsen, K., 2000. Gabbroic xenoliths from La Palma, Tenerife and Lanzarote, Canary Islands: evidence for reactions between mafic alkaline Canary Islands melts and old oceanic crust. Journal of Volcanology and Geothermal Research 103, 313-342.

Neumann, E.R., Griffin, W.L., Pearson, N.J., O'Reilly, S.Y., 2004. The evolution of the upper mantle beneath the Canary Islands: information from trace elements and $\mathrm{Sr}$ isotope ratios in minerals in mantle xenoliths. Journal of Petrology 45, 2573-2612.

Nicolas, A., 1976. Flow in upper-mantle rocks: some geophysical and geodynamic consequences. Tectonophysics 32, 93-106.

Nicolas, A., Poirier, J.P., 1976. Crystalline Plasticity and Solid State Flow in Metamorphic Rocks. Wiley, London. 444 pp.

Nicolas, A., Boudier, F., Boullier, A.M., 1973. Mechanisms of flow in naturally and experimentally deformed peridotites. American Journal of Science 273, 853-876.

Ortiz, R., Araña, V., Astiz, M., García, A., 1986. Magnetotelluric study of the Teide (Tenerife) and Timanfaya (Lanzarote) volcanic areas. Journal of Volcanology and Geothermal Research 30, 357-377.

Pera, E., Mainprice, D., Burlini, L., 2003. Anisotropic seismic properties of the upper mantle beneath the Torre Alfina area (Northern Apennines, Central Italy). Tectonophysics 370, $11-30$.

Prior, D.J., Boyle, A.P., Brenker, F., Cheadle, M.C., Day, A., Lopez, G., Peruzzo, L., Potts, G.J., Reddy, S., Spiess, R., Timms, N.E., Trimby, P., Wheeler, J., Zetterström, L., 1999. The application of electron backscatter diffraction and orientation contrast imaging in the SEM to textural problems in rocks. American Mineralogist 84, $1741-1759$.

Raitt, R.W., Shor, G.G., Francis, T.J.G., Morris, G.B., 1969. Anisotropy of the Pacific upper mantle. Journal of Geophysical Research 74, 3095-3109.

Raleigh, C.B., 1968. Mechanisms of plastic deformation of olivine. Journal of Geophysical Research 73, 5391-5406.

Rhodes, M., Davies, J.H., 2001. Tomographic imaging of multiple mantle plumes in the uppermost lower mantle. Geophysical Journal International 147, 88-92.

Robertson, A.H.F., Bernouilli, D., 1982. Stratigraphy, facies, and significance of late Mesozoic and Early Tertiary sedimentary rocks of Fuerteventura (Canary Islands) and Maio (Cape Verde Islands). In: von Rad, U., Hinz, K., Sarthein, M., Seibold, E. (Eds.), Geology of NW African Continental Margin. Springer Verlag, Berlin, pp. 498-525.

Robertson, A.H.F., Stillman, C.J., 1979. Submarine volcanic and associated sedimentary rocks of the Fuerteventura Basal Complex, Canary Islands. Geological Magazine 116, 203-214.

Roeser, H.A., 1982. Magnetic anomalies in the magnetic quiet zone off Morocco. In: Von Rad, U., Hinz, K., Sarnthein, M., Seibold, E. (Eds.), Geology of the Northwest African Continental Margin. Springer Verlag, Berlin, pp. 60-68.

Roest, W.R., Dañobeitia, J.J., Verhoef, J., Collette, B.J., 1992. Magnetic anomalies in the Canary Basin and the Mesozoic evolution of the central north Atlantic. Marine Geophysical Researches 14, 1-24.

Saruwatari, K., Ji, S.C., Long, C.X., Salisbury, M.H., 2001. Seismic anisotropy of mantle xenoliths and constraints on upper mantle structure beneath the southern Canadian Cordillera. Tectonophysics 339, 403-426.

Schmincke, H.U., 1973. Magmatic evolution and tectonic regime in the Canary, Madeira and Azores Island groups. Geological Society of America Bulletin 84, 633-648.

Schmincke, H.U., 1982. Volcanic and chemical evolution of the Canary Islands. In: von Rad, U., Hinz, K., Sarthein, M., Seibold, E. (Eds.), Geology of the Northwest African Continental Margin. Springer Verlag, Berlin, pp. 273-306.

Schmincke, H.U., Klügel, A., Hansteen, T.H., Hoernle, K., van den Bogaard, P., 1998. Samples from the Jurassic ocean crust beneath Gran Canaria, La Palma and Lanzarote. Earth and Planetary Science Letters 163, 343-360.

Shearer, P.M., Orcutt, J.A., 1986. Compressional and shear wave anisotropy in the oceanic lithosphere — the Ngendei seismic refraction experiment. Geophysical Journal of the Royal Astronomical Society 87, 967-1003.

Siena, F., Beccaluva, L., Coltorti, M., Marchesi, S., Morra, V., 1991. Ridge to hotspot evolution of the Atlantic lithospheric mantle: evidence from Lanzarote peridotite xenoliths (Canary Islands). J. Petrol. Spec. Lithosphere Issue, pp. 271-290.

Silveira, G., Stutzmann, E., Griot, D.A., Montagner, J.P., Victor, L.M., 1998. Anisotropic tomography of the Atlantic Ocean from Rayleigh surface waves. Physics of the Earth and Planetary Interiors 106, 257-273.

Silver, P.G., Chan, W.W., 1991. Shear wave splitting and subcontinental mantle deformation. Journal of Geophysical Research 96, $16429-16454$

Soedjatmiko, B., Christensen, N.I., 2000. Seismic anisotropy under extended crust: evidence from upper mantle xenoliths, Cima Volcanic Fiels, California. Tectonophysics 321, 279-296.

Stillman, C.J., Fúster, J.M., Bennell-Baker, M.J., Muñoz, M., Smewing, J.D., Sagredo, J., 1975. Basal complex of Fuerteventura (Canary Islands) is an oceanic intrusive complex with rift-system affinities. Nature 257, 469-471.

Tanimoto, T., Anderson, D.L., 1985. Lateral heterogeneity and azimuthal anisotropy of the upper mantle: Love and Rayleigh waves 100-250 s. Journal of Geophysical Research 90, 1842-1858.

Thomas, L.E., Hawkesworth, C.J., Van Calsteren, P., Turner, S.P., Rodgers, N.W., 1999. Melt generation beneath ocean islands: a UTh- Ra isotope study from Lanzarote in the Canary Islands. Geochimica and Cosmochimica Acta 63, 4081-4099.

Tommasi, A., Tikoff, B., Vauchez, A., 1999. Upper mantle tectonics: three-dimensional deformation, olivine crystallographic fabrics and seismic properties. Earth and Planetary Science Letters 168, $173-186$. 
Van Roermund, H.L.M., Boland, J.N., 1981. The dislocation substructures of naturally deformed omphacites. Tectonophysics $78,403-418$.

Vauchez, A., Garrido, C.J., 2001. Seismic properties of an asthenospherized lithospheric mantle: constraints from lattice preferred orientations in peridotite from the Ronda massif. Earth and Planetary Science Letters 192, 235-249.

Venables, J.A., Harland, C.J., 1973. Electron back-scattering patterns - a new technique for obtaining crystallographic information in the scanning electron microscope. Philosophical Magazine 27, $1193-1200$.

Verma, R.K., 1960. Elasticity of some high-density crystals. Journal of Geophysical Research 65, 757-766.

Vogt, P.R., 1974. Volcano spacing fractures and thickness of the lithosphere. Earth and Planetary Science Letters 23, 337-348.

Vollmer, F.W., 1990. An application of eigenvalues methods to structural strain domain analysis. Geological Society of America Bulletin 102, 786-791.
Watts, A.B., 1994. Crustal structure, gravity anomalies and flexure of the lithosphere in the vicinity of the Canary Islands. Geophysical Journal International 119, 648-666.

Wenk, H.R., Bennet, K., 1991. Modelling plastic deformation of peridotite with the self-consistent theory. Journal of Geophysical Research 96, 8337-8349.

Woodcock, N.H., 1977. Signification of fabric shapes using an eigenvalues method. Geological Society of America Bulletin 88, $1231-1236$.

Zeuch, D.H., Green, H.W., 1984. Experimental deformation of a synthetic dunite at high temperature and pressure. Tectonophysics 110, 233-262.

Zhang, S., Karato, S.I., 1995. Lattice preferred orientation of olivine aggregates deformed in simple shear. Nature 375, 774-777.

Zhang, S., Karato, S.I., Fitz Gerald, J.D., Faul, U.H., Zhou, Y., 2000. Simple shear deformation of olivine aggregates. Tectonophysics $316,133-152$. 